\title{
ESTUDIO MONOGRAFICO DEL ORDEN POLYTRICHALES EN ESPAÑA. (ENSAYO PARA UNA FLORA BRIOLOGICA ESPAÑOLA)
}

\author{
M. BRUGUES; C. CASAS (*) y M. ALCARAZ $(*)$
}

\section{RESUMEN:}

Cada vez es más patente la necesidad de una flora briológica española. A tal fin se pro. pone en esta comunicación el estudio de la familia Polytrichaceae en España, única que constituye el Orden Polytrichales, como base, esquema o ejemplo para realizar dicha flora.

\section{SUMMARY:}

The need for a Spanish bryologycal flora is becoming increasingly apparent. With this need in mind, this work proposes the study of the family Polytrichaceae in Spain, the only one which constitutes the Order Polytrichales, as a basis, scheme or example for the realisation of such a flora.

\section{ORDEN POLYTRICHALES}

Gametófitos con los caulidios erectos, rígidos, simples o ramificados; haz axial diferenciado, complejo (estenocistes, euricistes y estereidas) y con indicios de rastros filoidales. Filidios generalmente diferenciados en una vaina abrazadora y una lámina que posee lamelas longitudinales implantadas en su parte ventral por encima del nervio. Habitualmente dioicos. Acrocárpicos. Perístoma nematodonte dividido en 32-64 dientes cortos ligulados sobre una membrana basilar más o menos alta.

Comprende dos familias: Dawsoniaceae y Polytrichaceae. La primera de Australia y Malasia; sólo 5 géneros de las Polytrichaceae se hallan en Europa. Todos. ellos menos Psilopilum están representados en España.

\footnotetext{
Comunicación presentada al III Simposio Nacional de Botánica Criptogámica. Málaga, 1978. 


\section{FAMILIA POLYTRICHACEAE}

Gametófitos perennes con caulidios simples, a veces ramosos, erectos, cortos o elevados formando céspedes laxos o densos a partir de un rizoma rizoidal rastrero o de un protonema persistente. Los caulidios suelen ser desnudos en la base. Los filidios inferiores son escuamiformes y los superiores lanceolados a liguliformes, más o menos alargados con una base a veces en forma de amplia vaina membranosa; recorridos longitudinalmente por pocas a numerosas lamelas verdes; el margen del filidio es entero o dentado; el nervio fuerte, se introduce en el ápice y puede ser escurrente a veces ensanchado e indistinto en la base; las células cerca del ápice del filidio son casi isodiamétricas, lisas o a veces con pequeñas papilas, las de la base son rectangulares, lisas o finamente papilosas. Dioicas a veces sinoicas o polioicas. Grupos de anteridios terminales, discoidales, rodeados de amplios filidios perigoniales de color rojo, amarillo o marrón. Filidios periqueciales semejantes a los filidios normales. Seta larga, rígida, generalmente lisa. Urna erecta o inclinada, ovoide, cilíndrica o primática con 2-6 ángulos, con hipófisis o sin ella, con o sin estomas; caliptra cuculada lisa o fuertemente pelosa en el ápice; los pelos reflejos forman en este caso un denso fieltro que cubre totalmente o en parte la urna; opérculo redondeado o deprimido con rostro largo o corto; perístoma simple de 32-64 dientes, cortos, reunidos en el ápice por una fina membrana (epifragma) procedente de la columela.

Las especies de esta familia aparecen en suelos preferentemente húmedos, mojados, pantanosos, generalmente ácidos, en las zonas templadas y árticas del mundo.

1. Base de los filidios no o débilmente envainadora; nervio estrecho ocupando menos de la tercera parte de la lámina.

1. Base de los filidios claramente envainadora; nervio fuerte que ocupa casi toda la superficie del filidio, excepto en la base.

2. Margen de la lámina con un estrecho borde de células alargadas; lámina totalmente verde con 2-7 lamelas longitudinales.

3 Atrichum

2. Margen de la lámina sin borde de células alargadas; 10-16 lamelas.

4 Oligotrichum

3. Margen del filidio dentado por lo menos en la parte distal.

3. Margen del filidio entero. Unna prismática con hipófisis aparente.

1 Polytrichum

4. Células marginales de las lamelas más o menos ovoides, lisas, poco papilosas o emarginadas. Urna prismática, raramente casi cilindrica; hipófisis aparente y grandes estomas en la base; peristoma de 64 dientes.

1 Polytrichum

4. Células marginales de las lamelas esféricas casi lisas o muy papilosas. Unna cilíndrica, nunca angulosa sin hipófisis ni estomas; peristoma de 32 dientes. 

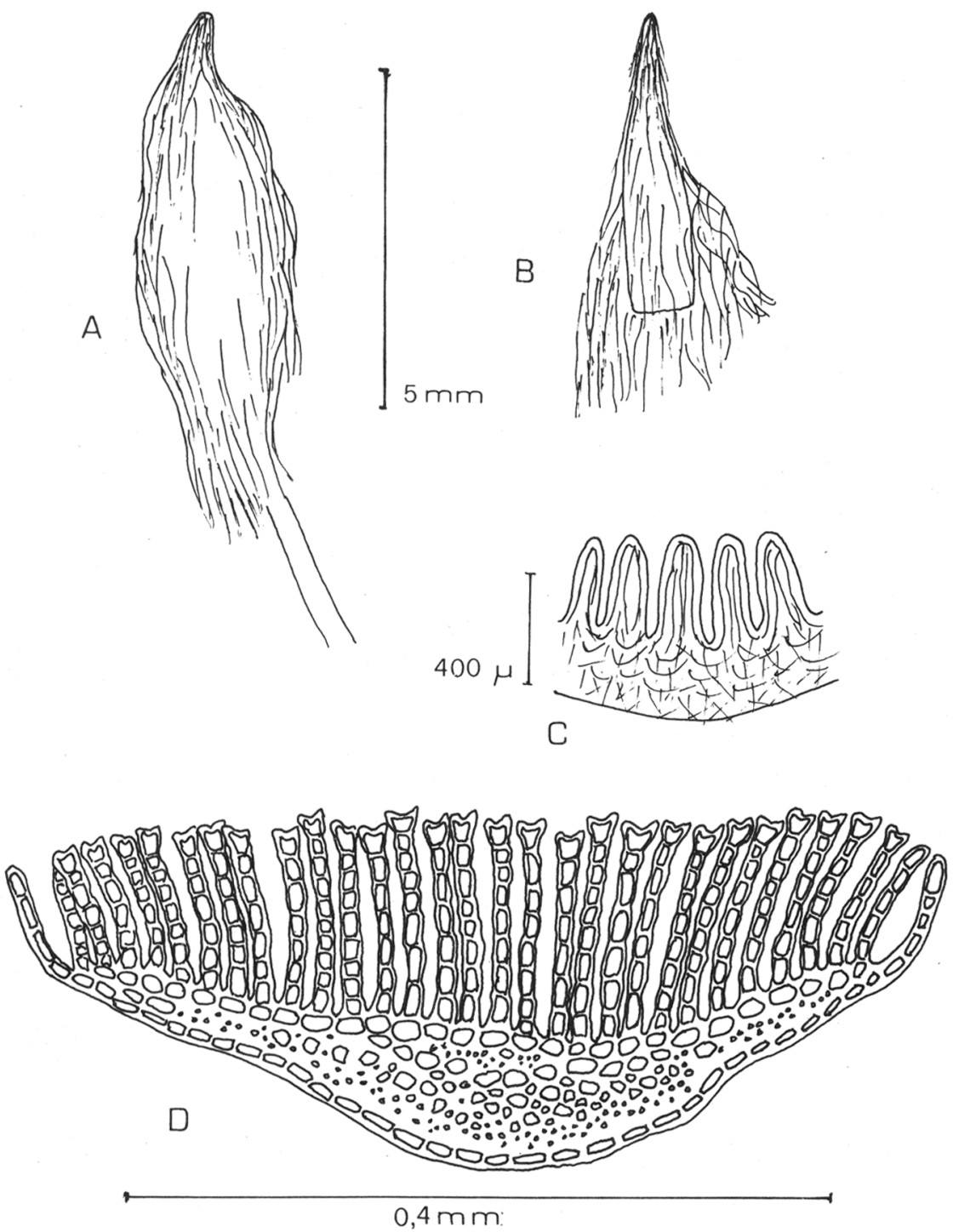

Fig. 1.-A, caliptra de Polytrichum piliferum Hedw. B, caliptra de Polytrichum alpinum $\mathrm{Hedw}$. C, peristoma de Polytrichum piliferum Hedw. D, corte transversal del filidio de Polytrichum commune Hedw. 


\section{POLYTRICHUM Hedw.}

Generalmente grandes musgos, robustos, con caulidios simples, a veces ramosos, reunidos en amplios céspedes. Dioico. Filidios de base membranosa abrazadora, incolora, amarillenta o rojiza a marrón, rápidamente o gradualmente estrechados en una lámina oval o lineal lanceolada, erecta, patente o recurvada; la parte ventral, sobre el nervio, se halla recubierta por numerosas lamelas verdes longitudinales; margen de la lámina en su parte superior, plano dentado o incurvado entero; nervio ancho o indistintamente limitado en la parte superior, más estrecho y delimitado en la base; células cerca del ápice del filidio cuadradas o poligonales, en la base abrazadora largas rectangulares. Seta larga, rígida, lisa. Urna erecta o inclinada, corta o alargada, angulosa o raramente cilíndrica; hipófisis generalmente aparente separada del resto de la urna por una estrangulación más o menos profunda; grandes estomas en la base de la urna; células del exotecio lisas o mamilosas; dientes del-perístoma, ligulados, estriados longitudinalmente; la membrana basal casi tan alta como los dientes o más corta; opérculo redondeado cónico con un apículo corto o rostrado. Caliptra cuculada con abundantes pelos apicales reflejos que forman un amplio fieltro mitriforme de color marrón a casi blanco.

1. Margen del filidio fuertemente dentado y plano.

1. Margen del filidio entero, crenado o dentado en la punta, en la parte superior ampliamente incurvado sobre las lamelas.

2. Urna cilíndrica, ovoide un poco inclinada. Dientes del borde del filidio 1-3 celulares; células marginales de las lamelas ovoides y fuertemente papilosas.

1 P. alpinum

2. Urna prismática (4-6 ángulos). Dientes del borde del filidio unicelulares; células marginales de las lamelas ovoides, planas o emarginadas, lisas o poco papilosas.

3. Células marginales de las lamelas planas o emarginadas. Urna prismática o cúbica con 4 ángulos; hipófisis muy visible; células del exotecio mamilosas.

4 P. commune

3. Todas las células marginales de las lamelas son ovoides o estéricas. Células del exotecio lisas o casi.

4. Lámina del filidio con 5-15 o más filas de células de 10-14 nm. Unna ovoide poco angulosa cubierta en parte por la caliptra; opérculo con rostro largo.

2 P. longiesetum

4. Lámina del filidio con 3-6 filas de células de 9-12 nm. Urna oblonga con 4-6 ángulos, cubierta totalmente por la caliptra.

3 P. formosum

5. Filidio obtuso o apiculado por la escurrencia del nervio. Urna esférica u ovoide con 6 ángulos obtusos, marrón, cubierta en parte por la caliptra. Planta alpina.

5. Filidio prolongado en una arista dentada.

6. Arista del filidio la rga, hialina.

o. Arista del filidio marrón.

$5 P$. sexangulare

6 P. piliferum

7 P. juniperinum

(nm) micras 


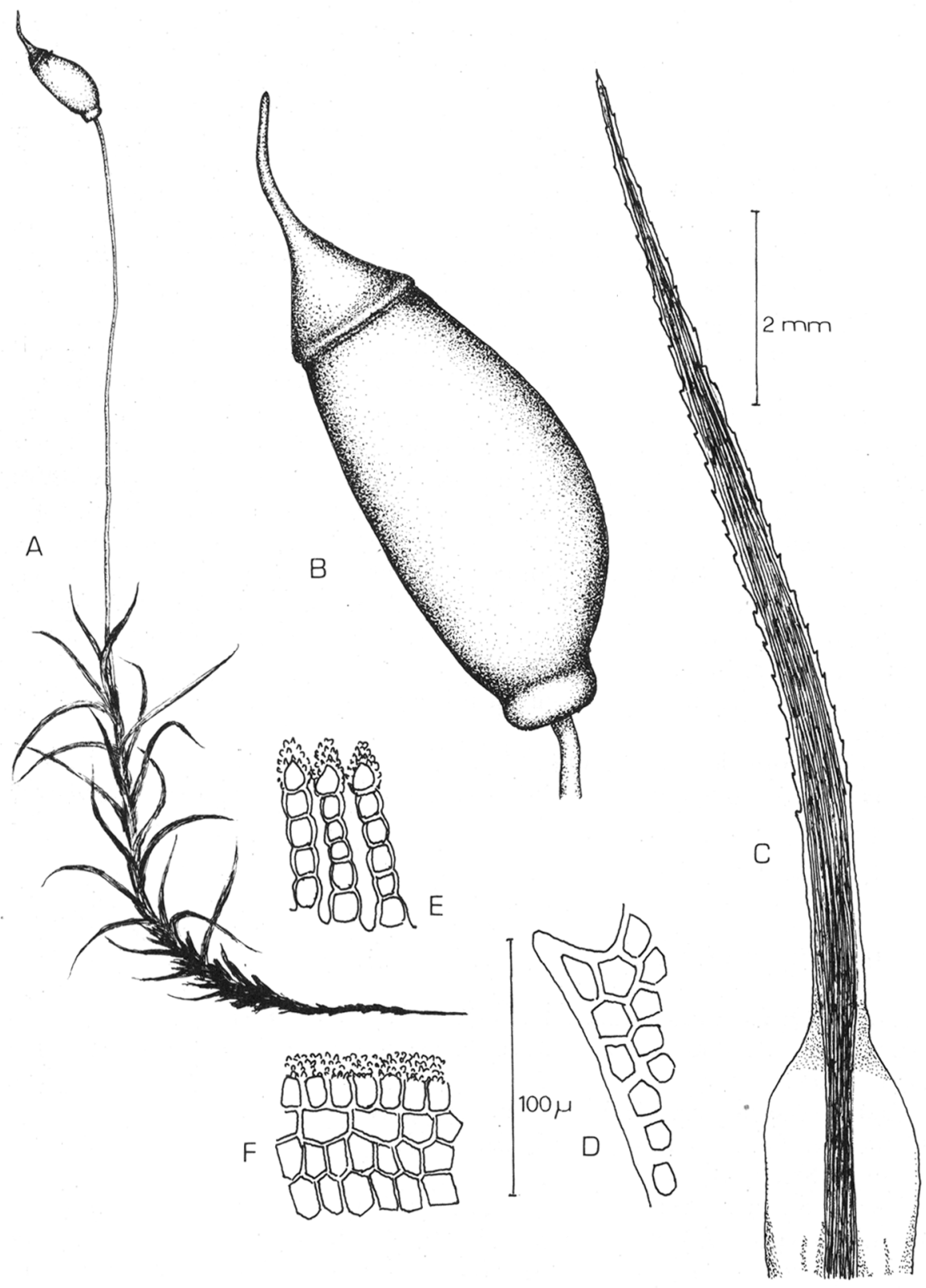

Figura 2.-Polytrichum alpinum Hedw. Polytrichastrum alpinum (Hedw.) G.L. Sm. A, planta (x 2). B, urna con opérculo (x 12). C, filidio. D, margen del filidio. E, sección de la lamela. F, lamela. 
Polytrichum alpinum Hedw. Sp. Mus. 1800. Polytrichastrum alpinum (Hedw.) G.L.Sm. Pogonatum alpinum Röhl.

Gametótito simple o ramificado. Caulidio de 10 hasta $20 \mathrm{~cm}$. nudo en la parte inferior, de color verde oscuro y marrón en el interior. Filidio de base envamadora a marillenta o marrón, gradual o rápidamente estrechada en una lámina de 4 $10 \mathrm{~mm}$., lanceolada, erecta, patente o recurvada, con el borde plano y 3-5 filas du células; margen con grandes dientes $1-3$ celulares; células de la mitad superior de la lámina cuadradas $10-14 \mathrm{~nm}$. en la base envainadora muy largas y estrechas; nervio escurrente en una arista marrón y con el dorso dentado cerca de la punta; lamelas numerosas compuestas de 5-9 filas de células de 10-20 nm. con las células marginales ovoides, de pared externa muy engrosada y papilosa. Seta flexuosa de 3-5 cm., a marilla con la base rojiza. Urna larga o corta, cilíndrica o casi, inclinada y ligeramente asimétrica incurvada o erecta y casi simétrica, ferruginosa que ennegrece después de la esporosis; hipófisis poco aparente; células del exotecio lisas, rectangulares o cuadradas, a veces de forma irregular, hacia la mitad de la urna de 20 hasta $40 \mathrm{~nm}$.; dientes del perístoma de longitud variable, de 160 a $300 \mathrm{~nm}$., con membrana basal corta (16 $\mathrm{nm}$.); epifragma denticulado; opérculo cónico con rostro largo y oblicuo; caliptra rojo marrón pelosa que cubre sólo parte de la urna. Esporas finamente papilosas de $18-20 \mathrm{~nm}$. Esporófito en verano. Forma laxos o densos céspedes en hábitats expuestos o sombríos, en suelos húmedos o secos, ácidos, pero también en suelos calcáreos. En el piso subalpino, más rara en el piso alpino y nival. Muestra testigo: Pal, Riu del Prat del Bosc, $1.900 \mathrm{~m}$. Andorra. Leg. et det. C. Casas, 14-VII-1978 (BC).

Mesófila, esciófila, terrícola, calcífuga tolerante.

Cosmopolita.

var. septentrionale $(S w$.$) Lindb.$

Caulidios más cortos de $2 \mathrm{~cm}$, filidios subsecundos de $5 \mathrm{~mm}$, urna casi erecta y globosa.

\section{Distribución en España}

Asturias.-O: Cueto de Arbás (Herb. Durieu in Sim. 1977).

Aragón.-Hu: Crabioules (Spr. 1849). Puerto de Oo (Mull. 1854). Z: Moncayo (Ton. 1903).

Andorra.-Pessons; Ensagents; Vall de Riu (Cas. 1951b).

Catalunya.-GE: Núria (Vay. 1882; Cas. 1952; V. All. et al. 1976). L: Vall de St.

Nicolau (Ser. 1956).

León.-S: Sierra de Béjar (Casar. 1915; Lui 1924).

Castilla la Vieja.-S: Peña Labra (Cas. 1953). BU: Pineda de la Sierra, en la Concha (Leg. Font Q. in Cas. 1975a). SG: San Ildefonso (Herb. Durieu in Sim. 1977). AV: Gredos (Cil. 1945).

Castilla la Nueva.-M: Sierra de Guadarrama (Casar. 1915).

Andalucía.-GR: Sierra Nevada, en la laguna de las Yeguas (V. All. et al. 1956). var. septentrionale $\left(S_{w}.\right)$ Brid. (= P. septentrionale $\left.S w.\right)$

Andalucía.-GR: Sierra Nevada en el picacho del Veleta (Boi. 1939-45). 


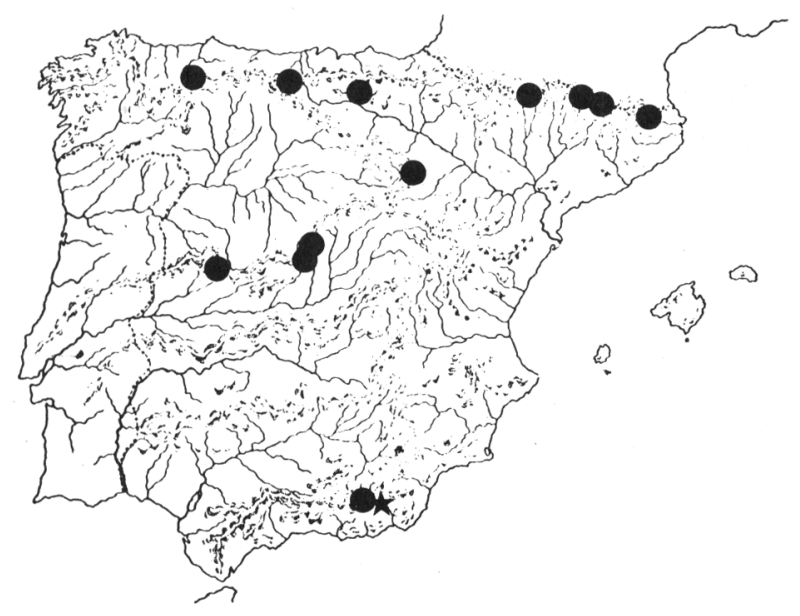

Polytrichum alpinum Hedw. Polytrichastrum alpinum (Hedw.) G.L. Sm. Distribución conocida en España. $\star v a r$ septentrionale (Sw.) Brid.

Polytrichum longisetum Sw. ex Brid. Journ. Bot. 1801. Polytrichastrum longisetum (Sw.) G.L. Sm. Polytrichum gracile Dicks.

Gametófito erecto de 3-6 hasta $10 \mathrm{~cm}$. Caulidio simple, nudo sin filidios en la base pero con denso fieltro rizoidal blanquecino. Filidios secos aplicados al caulidio, húmedos erectos, erecto patentes o patentes y recurvados de 5-7 mm, lineal-lanceolados con la parte inferior ensanchada gradual o abruptamente en una base envainadora y terminados en una punta aguda; lámina de anchura variable, estrecha e incurvada en el ápice y con 5-15 filas de células hacia la mitad del filidio, éstas cuadradas, redondas o elíptico-transversas de $10-14 \mathrm{~nm}$, las de la base gradualmente alargadas y cerca del nervio de $50-80 \mathrm{~nm}, 3-4$ veces más largas que anchas; margen con dientes unicelulares desde el ápice hasta cerca de la base envainadora; nervio fuerte, escurrente en una punta marrón denticulada, 20-40 lamelas de 70-90 nm. de ancho en la mitad del filidio, compuestas de 5-7 filas de células lisas redondeadas, casi todas iguales de $14 \mathrm{~nm}$; las del margen apenas engrosadas en la punta. Filidios periqueciales con base envainadora más larga e hialina. Seta de $3-5 \mathrm{~cm}$, flexuosa, a marilla, anaranjada en la base. Urna erecta, inclinada al envejecer, ovoide, ángulosa con 5-6 ángulos poco marcados, corta o alargada, estrechada en la boca; hipófisis aparente sin profunda estrangulación; células del exotecio isodiamétricas o cortamente rectangulares $20-40 \mathrm{~nm}$; opérculo redondeado con largo rostro oblicuo; perístoma con 64 dientes a veces confluentes, largos, desiguales (cerca de 240$400 \mathrm{~nm}$.); membrana basal corta. Esporas 20-27 nm. (18-22) finamente papilosas o casi lisas. Esporófito en verano, mayo-junio.

Forma densos céspedes en hábitats húmedos, suelos pantanosos, bosques, borde de lagos y riberas, turberas. M.T.: Maranges al borde del Estany de Malniu con Sphagnum. 2.200 m. (Girona). Leg. et det. C. Casas, 23-VI-1958 (BC).

Mesófila, humícola, calcífuga.

Cosmopolita. 
La distinción con Polytrichum formosum es difícil. Los céspedes son más compactos, las células de la parte inferior de los filidios más anchas y cortas, las la melas menos numerosas, la urna más pequeña, y menos angulosa, el opérculo con rostro más largo y principalmente el hábitat en turberas y suelos pantanosos.
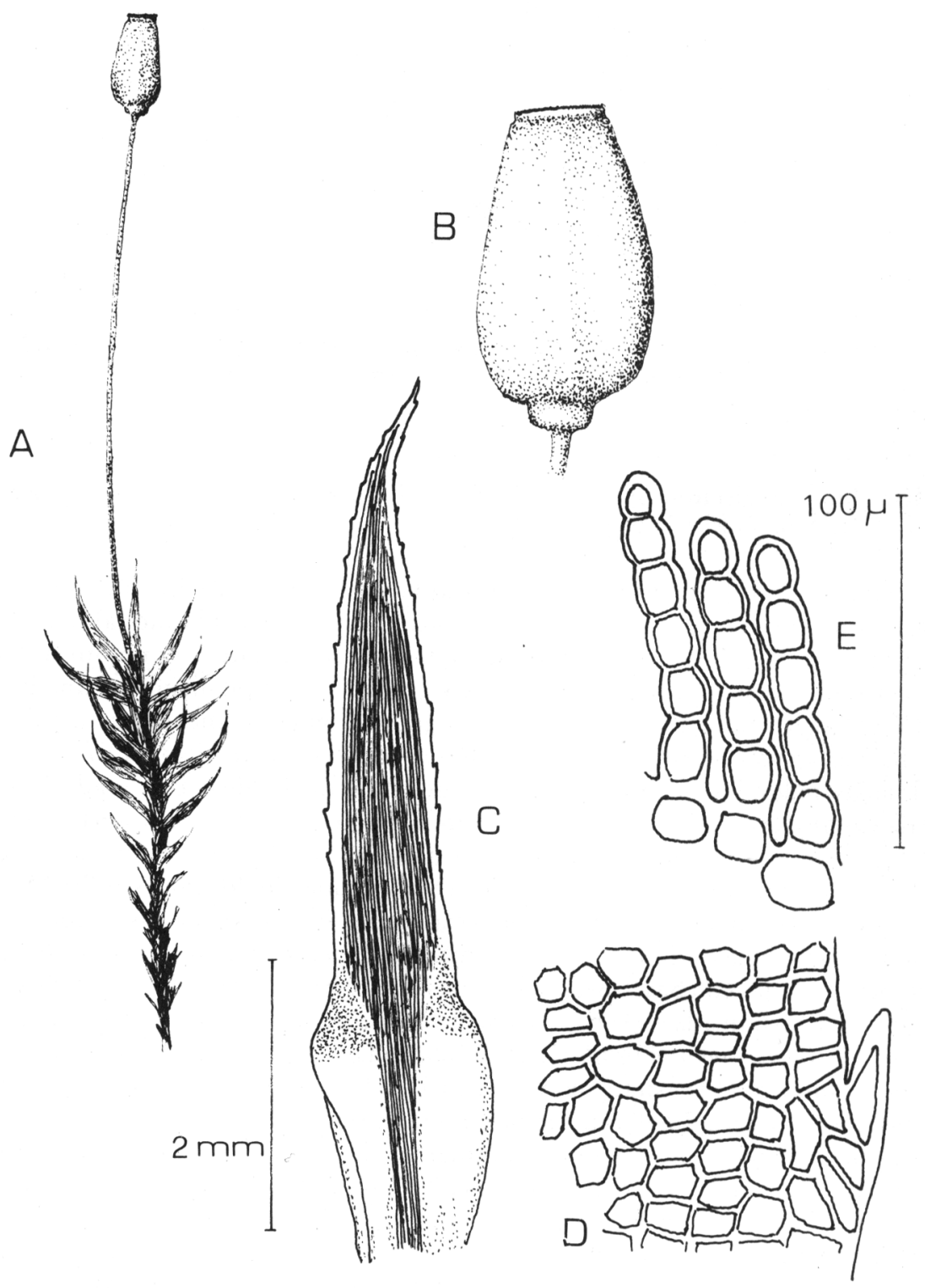

Fig. 3.- Polytrichum longisetum Sw. ex Brid. Polytrichastrum longisetum (Sw:) G.L. Smith A, planta (x 2). B, urna (x 6). C, filidio. D, margen del filidio. E, sección de la lamela. 


\section{Distribución en España}

Andorra.-Al borde de un lago, bajando del pico de Pessons en el Valle de Valira d'Orient (Corb. 1897).

Catalunya.-GE: Estany de Malniu (Casas BC).

Hay una cita de CILLERO de Gredos sin especificar localidad, muy dudosa y que debe ser comprobada.

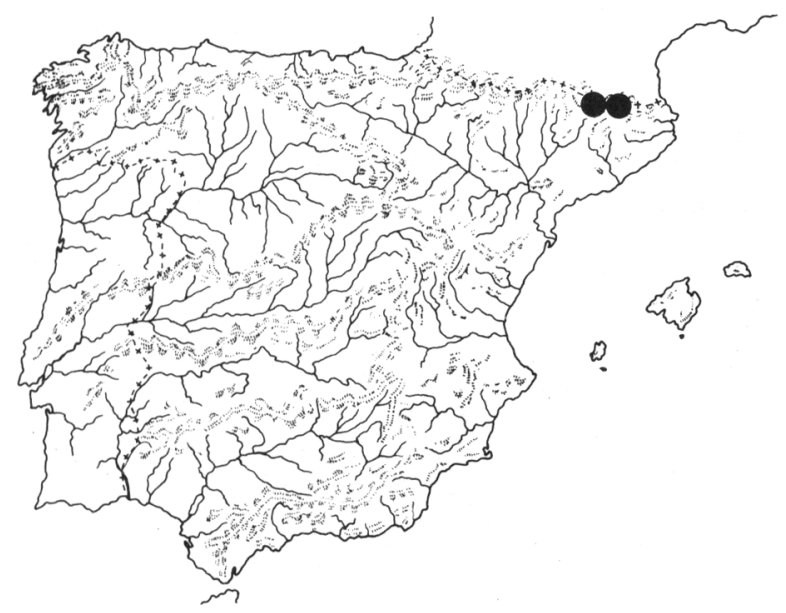

Polytrichum longisetum Sw. ex Brid. Polytrichastrum longisetum (Sw.) G.L. Sm. Distribución conocida en España

Polytrichum formosum Hedw. Sp. Musc., 1801. Polytrichastrum formosum (Hedw.) G.L. Sm. Polytrichum attenuatum Menz.

Gametófito verde oscuro o glauco de 5-10 hasta $15 \mathrm{~cm}$. Caulidios erectos o ascendentes, simples o furcados, con rizoides en la base. Filidios inferiores escuamiformes, los superiores de 8-12 mm., erectos en estado seco, erecto patentes, patentes o recurvados en estado húmedo; base envainadora, bruscamente prolongada en una lámina lanceolada, estrecha, de punta aguda y borde plano provisto de fuertes dientes unicelulares; la parte unistratificada de la lámina posee de 3-6 filas de células, éstas son redondeadas o cuadradas con pared más o menos gruesa, 9-12 $\mathrm{nm}$; en la base son gradualmente alargadas y estrechas y aún más en el borde cerca de la base 6-10 veces más largas que anchas (son más largas y estrechas que en $P$. longisetum); 60-70 lamelas de 4-5 filas de células lisas, más o menos hexagonales de 10-11 nm; la sección transversal de las la melas muestra la célula marginal oval con la pared más engrosada en la punta; nervio fuerte y dentado en la parte superior, escurrente en una punta marrón dentada. Filidios periqueciales largos 13-15 mm, acuminados, ligeramente dentados, erectos, de base la rga y envainadora. Seta a marilla y rojiza en la base, flexuosa de 4-8 $\mathrm{cm}$. Urna amarillo-verdosa, erecta, con 5-6 ángulos raramente 4 , en la madurez inclinada hasta horizontal, amarillo marrón 
después de la esporosis; hipófisis visible; células del exotecio isodiamétricas mamilosas pero sin papilas 24-32 nm; opérculo cónico apiculado de borde rojo; boca de la urna ancha; dientes del perístoma pálidos, cortos $(120-280 \mathrm{~nm}$.) papilosos, membrana basal corta $1 / 3$ de la longitud; la caliptra cubre totalmente la urna. Esporas amarillo-ocráceas $14-18 \mathrm{~nm}$. finamente punteadas. Esporófito en verano. Forma céspedes laxos en hábitats húmedos o secos en los bosques y landas hasta el piso subalpino, más raro en el alpino. M.T.: Collformic en el interior del hayedo. 1.200 m. (Barcelona). Leg. et det. C. Casas, 28-VIII-1978 (BC).

Mesófila, esciófila, terrícola, calcífuga tolerante.

Circumboreal.

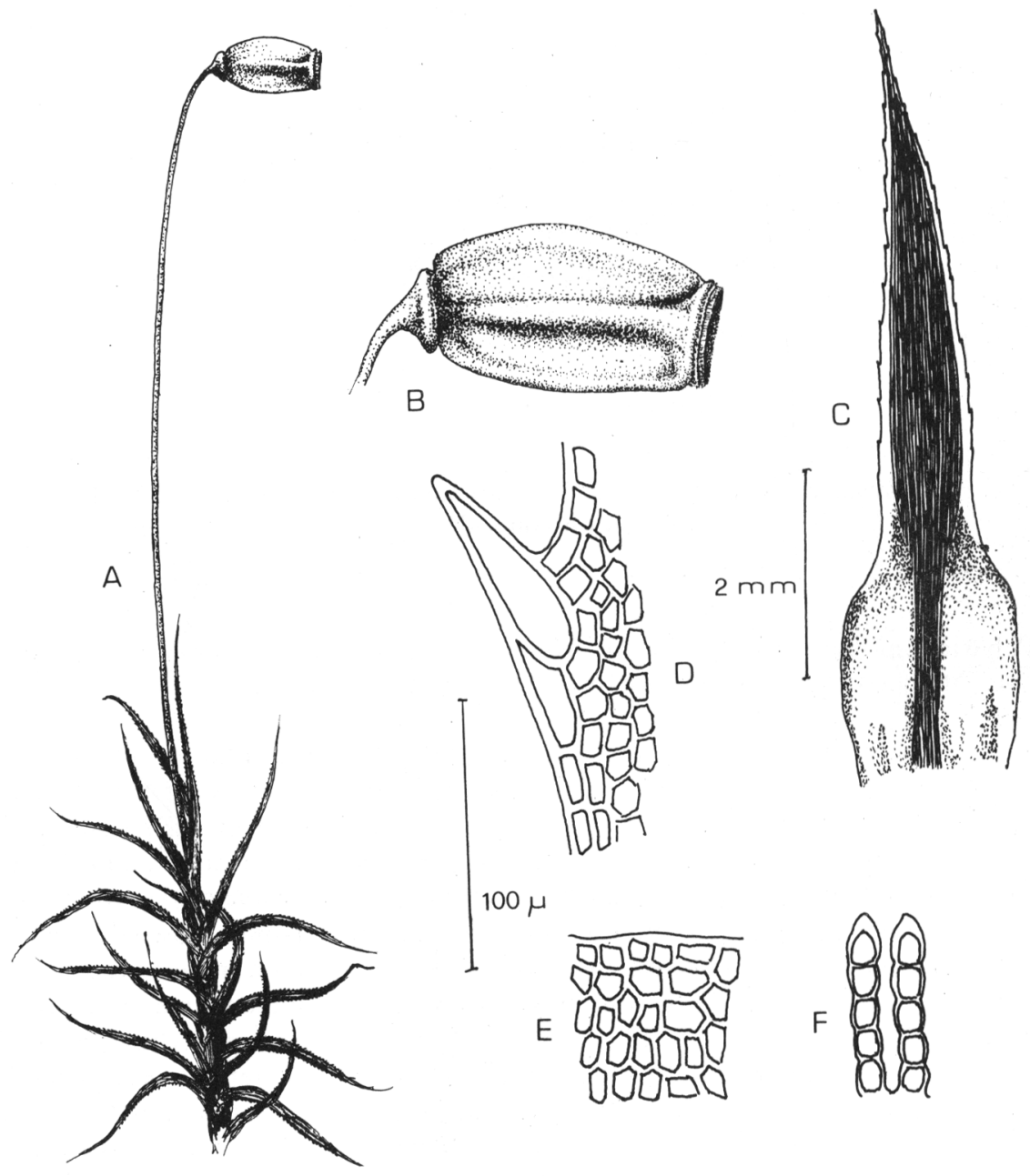

Fig. 4.-Polytrichum formosum Hedw. Polytrichastrum formosum (Hedw.) G.L. Sm. A, planta (x 2). B, urna (x 12). C, filidio. D, margen del filidio. E, lamela. F, sección de la lamela. 
Distribución en España

Galicia.-Frecuente en toda Galicia (Casar. 1915). C: Pico Sagro, cerca de Santiago (Mul. 1854). Cambre (Run. 1964). PO: Porriño (Run. 1964). Monte Galliñeiro (Seoane in Cas. 1972).

Asturias.-Cangas de Tineo (Lev. et al. 1880). Cangas de Onís (P. All. 1928b); Covadonga; Puerto Pajares (Casar. 1915). Gijón (Cor. 1951). Covadonga (Run 1964). Páramo; Monte Grande; Monte de la Puerca (Sim. 1973). Gobiendes (Sin. et al. 1973). Puerto Ventana (Sim. 1973). Faro de Peñas (Sim. et al. 1974) Beleño (Sim. et al. 1975). Asturias (Herb. Durieu in Sim. 1977).

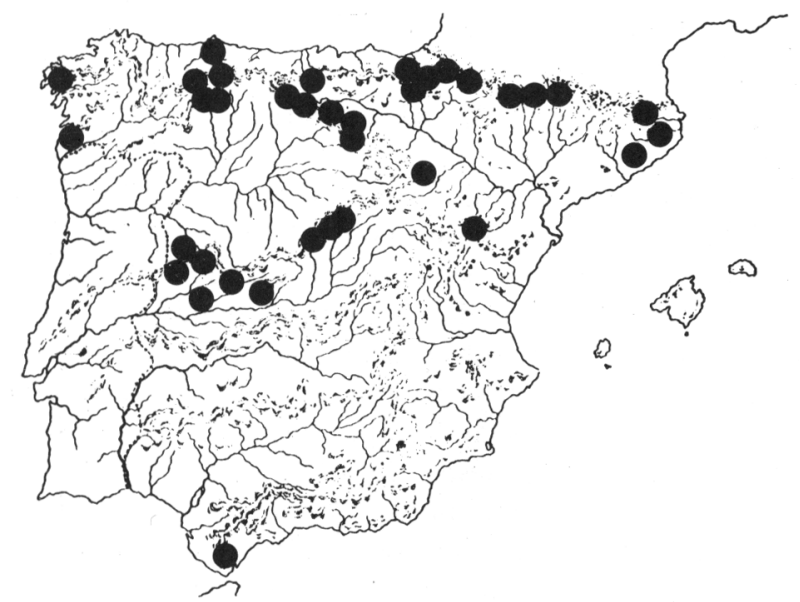

Polytrichum formosum Hedw. Polytrinchastrum formosum (Hedw.) G.L. Sm. Distribución conocida en España

País Vasco.-Común en todo el territorio (V. All. 1955). SS: Al borde del río Deva (P. All. 1928b).

Navarra.-NA: Valle de Vertiz (Lac. 1885). Sta. Cruz de Campezo (Fue. et al. 1975). Puerto de Azpiroz (Cas. 1972). Sierra de Leyre (Cas. et al. 1977b).

Aragón.-HU: Valle de Ansó (V. All. et al. 1962a). Pineta (Cas. 1961). Panticosa (Cor. 1951). Z: Moncayo (Ton. 1903). TE: Sierra de Albarracín (Leg. Mariné in Cas. et al. 1977).

Catalunya.-L: Arán (Casar 1915). Vall de Sant Nicolau (Ser. 1956). Por de la Bonaigua (V. All. et al. 1962b). Viella (Cor. 1951). GE: Núria (V. All. et al. 1976). Montseny (Casar. 1915; Cas. 1959-60). Estunes (Bar. 1920). Sant Llorenç de la Muga (Bru. et al. 1974). B: Aiguafreda; Tibidabo (Cas. et al. 1956). Vic (Mas. 1877). Campins; Aiguafreda; Coll Formic (Cas. 1959-60).

León.-SA: Candelario (Casar. 1915). Tejares; Lumbrales; Sierras de Ciudad Rodrigo; Sierra de Jálama (Lui. 1924). Las Batuecas (Cor. 1951). L: Villablino (P. All. 1928c).

Castilla la Vieja.-S: Bárcena (Rol. 1897). LO: Ortigosa de Cameros (Ton. 1906). Santo Domingo de la Calzada (Cor. 1951). Cerca de Pajares (V. All. et al. 1956). 
Puerto de Piqueras; Villoslada de Cameros (Cas. 1975a). BU: Soncillo (Herb. Laz in Casar. 1915). Obarenes (P. All. 1930). Pineda de la Sierra; Covaleda (Cas. 1975a). Soncillana (Fol. et al. 1917). PA: Piedras Luengas (Lev. et al. 1880). Pozo de Curavacas; Cervera de Pisuerga (Cas. 1953). SG: San Ildefonso (Herb. Durieu in Sim. 1977).

Castilla la Nueva.-M: El Paular (Cor. 1954). Sierra de Guadarrama (War. 1911). Siete Picos (Cor. 1951). Ventorrillo; Peñarcón; Puerto de Navacerrada (Casar. 1915). GU: Campillo de Ranas (Ladero in Cas. 1972).

Extremadura.-CC: Serradilla (Riv. 1897). Yuste (Cor. 1953). Sierra de Jálama (Lui 1924).

Andalucía.-CA: Sierra de Luna (V. All. et al. 1945).

Polytrichum commune Hedw. Sp. Musc. 1801.

Gametófito de 10-40 cm. Caulidios simples, raramente bifurcados, erectos flexuosos, denudados en la base. Filidios largos 10-15 mm. lanceolado-acuminados, patentes o erecto-patentes, más o menos recurvados en estado húmedo, erecto flexuosos en seco; base envainadora oblonga, membrana amarillento-hialinà; margen plano fuertemente dentado con dientes unicelulares hasta cerca de la base; borde hialino por encima de la base; nervio escurrente en una punta marrón denticulada; lámina compuesta de 5-9 filas de células de $14 \mathrm{~nm}$, en la base muy alargadas; 30-60 lamelas compuestas de 4-6 filas de células, las marginales más grandes, emarginadas, forman en el borde un surco acanalado. Filidios periqueciales internos membranosos envainadores de $18-20 \mathrm{~mm}$, sin lamelas, borde hialino y arista larga formada por la escurrencia del nervio. Los caulidios masculinos y sus filidios son más pequeños. Seta larga, hasta $12 \mathrm{~cm}$, rojiza brillante y a veces flexuosa. Urna tetrágona, a veces cúbica, erecta o inclinada al envejecer; bipófisis discoidal separada de la urna por una profunda estrangulación; las células del exotecio, con una pared más o menos fina, rectangulares, cuadradas o hexagonales tienen una papila cónica en cada una, en cuyo ápice hay un pequeño poro estrecho, elíptico; opérculo convexo deprimido con un apículo muy corto; dientes del perístoma de 240-320 $\mathrm{nm}$. con una membrana basal alta, $80-120 \mathrm{~nm}$; caliptra amarillo dorada que cubre totalmente la urna. Esporas de 10-12 nm, amarillentas, lisas o casi. Esporófito en verano.

Generalmente forma céspedes laxos, extensos más o menos profundos sobre suelo húmedo, sombrío, suelos encharcados, turberas, en el interior de los bosques desde el piso inferior hasta el piso subalpino y la zona inferior del alpino. M.T.: Vallferrera, Pirineo Central (Lleida), al borde de un arroyo en el interior del abetal 1.800 m. Leg. et det. C. Casas, 12-VII-1961 (BC).

Mesófila, higrófila, esciófila, humícola, calcífuga tolerante.

Cosmopolita.

var. perigoniale (Michx.) Hamp.

Caulidios más cortos $5-8 \mathrm{~cm}$, células marginales de las la melas más estrechas, irregularmente acanaladas en el extremo libre, o casi planas; urna más corta, casi cú- 
bica; filidios periqueciales decolorados, gradualmente subulados con la punta entera o dentada.

var. minus Weis. var. bumile Sw.

Semejante a la var. perigoniale pero los filidios periqueciales más bruscamente estrechados en una corta subula.

CORTES (1949) estudió ejemplares procedentes de diferentes localidades españolas determinados unos como var. perigoniale y otros como var. minus. Observó que los caracteres propuestos como diferenciales son muy variables. Por lo que se refiere a España, según Cortés, no puede mantenerse una distribución clara por lo que considera ambas denominaciones sinónimas.

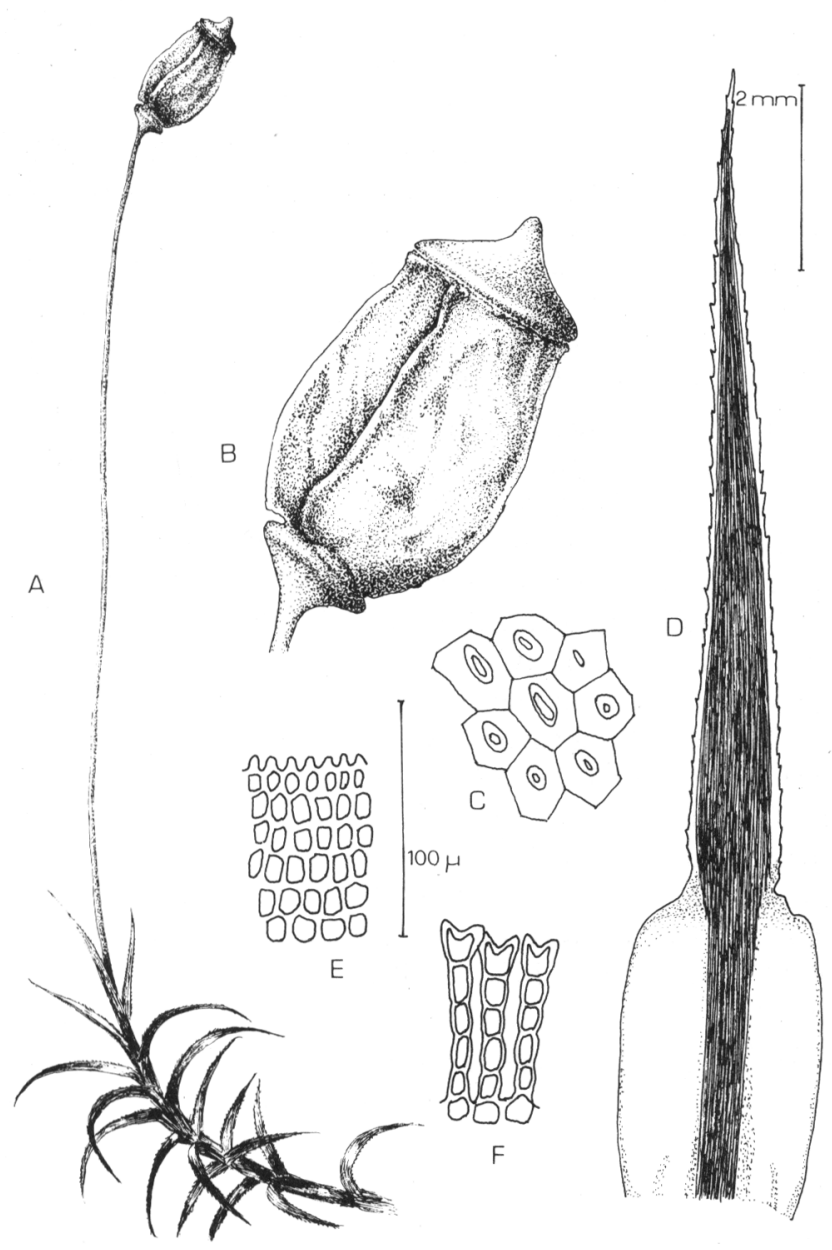

Fig. 5.-Polytrichum commune Hedw. A, planta (x 2). B, urna con opérculo (x 6). C, células del exotecio. D, filidio. E, lamela. F, sección de la lamela. 


\section{Distribución en España}

Galicia.-LU: Cerca de S. de Meira (V. All. et al. 1956). PO: Tuy (Seoane in Cas. 1972). C: Santiago (P. All. 1928a; Tex. in Col. 1889).

Asturias.-O: Verdicio (Sim. et al. 1974). Puerto Ventana (Sim. 1973). Cueto de Arbás (Herb. Durieu in Sim. 1977; Lag. in Col. 1889). Valle de Naviego (Gay. 1836).

País Vasco.-SS: Monte Jaizquíbel (V. All. 1955). BI: Elorrio (V. All. 1955).

Navarra.-NA: Endarlaza; Vertiz; Burguete; Pto. de Velate (V. All. 1955). Roncesvalles; Burguete (Née in Col. 1889). Puerto Ibañeta (Fuer. in Cas. 1975b). Aragón.-HU: Bielsa (Cam. y Los. in Col. 1889). TE: Losilla (Asso in Los. 1867). Sierra del Tremedal (Cas et al. 1977a).

Andorra.-Vall de Tristaina (Cas. 1975b).

Catalunya.-L: Vallferrera (Llensa 1941). Aran (Villiers in Col. 1889). GE: Núria (Vay. 1882). B: Llinás de Berga (Llensa 1941). Montseny (Pourret in Col. 1889). Montserrat (Bout. in Col. 1889). Estas dos últimas citas no se han comprobado hasta el momento. Parece seguro que no puede existir en Montserrat, montaña seca y de substrato calcáreo, mientras que es más probable su existencia en la montaña del Montseny. No obstante, hasta que no se compruebe efectivamente su presencia es mejor no tener en cuenta la cita de Pourret. En la montaña del Montseny es muy abundante el $P$. formosum con formas grandes hasta de más de $30 \mathrm{~cm}$. que bien pueden inducir a error.

León: LE: Pinar de Lillo (Izco in Cas. 1975c). Brañuelas; Busdongo (P. All. 1928c). SA: Ciudad Rodrigo; Sierra de Béjar; Las Batuecas (Lui. 1924).

Castilla la Vieja.-S: Santander (Sal. in Col. 1889). AV: Montes de Avila, Hoyoquesero (Quer in Col. 1889). BU: Quintanar de la Sierra; Pineda de la Sierra (Font Q. in Cas. 1975a). Soncillana (Fol. et al. 1917). SO: Entre Cidones y Vinuesa; Laguna Negra; Puerto de Piqueras (Cas. 1975a). Laguna Verde; Castillo de Vinuesa (Mont. in Cas. 1975a). Cebollera (Casar. et al. 1912). LO: San Millán de la Cogolla (Lag. in Col. 1889). Sierra de la Hez (Poz. in Col. 1889). SG: San Ildefonso (Née in Col. 1889). Peñalara; Navafría (Casar. et al. 1912).

Castilla la Nueva.-M: Balsaín; Peña Citores (Casar. et al. 1912). El Paular (Quer, Née y Lag. in Col. 1889). Cercanías de Madrid (P. de Esc. in Col. 1889). Colmenar Viejo; Escorial (Rodr. in Col. 1889).

Extremadura.-Guadalupe (Cor. 1951). Sierra próxima a Trujillo (H. de Greg. in Col. 1889). Bazagona; Hervás; Gredos (Riv. 1897). Puerto de Santa Clara a San Martín de Trevejo; Sierra de Eljas (Cor. 1953).

Andalucía.-CA: Alcalá de los Gazules; Grazalema; Cerro de San Cristóbal (Clem. in Col. 1889). SE: Puebla de los Infantes; Pedroso; Cazalla (Gon. 1883). Estas citas de Andalucía deben comprobarse, es muy probable que se hayan confundido con P. formosum. Ya Casares indica que precisa una revisión de todas las citas de España.

var. minus Weis.

Galicia.-Variedad más común en Galicia (Casar. 1915; Lui 1918). LU: Entre Meira y Lugo (V. All. et al. 1956). C: Santiago (P. All. 1928a).

León.-SA: Sierra de Jálama (Lui 1924). La Alberca; Peña de Francia (Cor. 1951). 
Castilla la Nueva.-M: Peñalara (Lev. et al. 1880; V. All. et al. 1956). Puerto de los Cotos (V. All. et al. 1956). Según Casares (1912) los muchos ejemplares de Polytrichum recogidos en los sitios donde esta variedad fue indicada por Levier todos e ran $P$. perigoniale.

Extremadura.-CC: Guadalupe; Villuecas (Cor. 1951).

var. perigoniale (Michx.) Hamp.

Galicia,-PO: Pontevedra (Run. 1964).

Castilla la Nueva.-Peñalara (Casar. 1915).

Extremadura.-Puerto de San Martín (Lui 1924; Cor. 1953). Guadalupe; carretera desde el Puerto de Santa Clara a San Martín de Trevejo; Las Villuercas (Cor. 1953). Andalucía.-GR: Sierra Nevada, en el Barranco de San Juan (Est. et al. 1975; Gil. 1973).

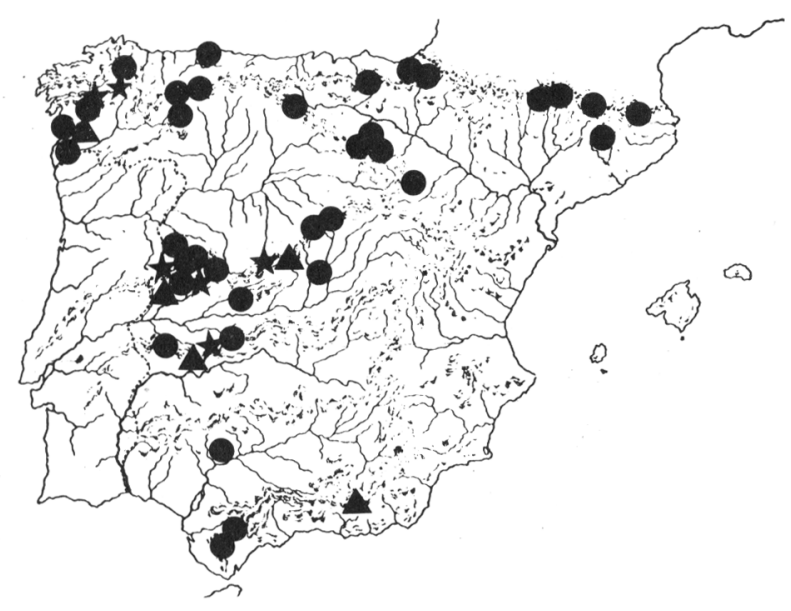

Polytrichum commni Hedw. Distribución conocida en España $\star$ var. minus Weis. A vir. perigoniale (Michx.) Hamp.

Polytrichum sexangulare (Flörke ex Hoppe) G.L. Smith

Gametófito verde hasta marrón de $1 / 2$ a $8 \mathrm{~cm}$. Caulidios simples furcados, erectos o decumbentes nudos o con escasos rizoides. Filidios de $5 \mathrm{~mm}$. rígidos, brillantes, cortos, linear-lanceolados, obtusos o con corto a pículo, erecto patentes a veces ligeramente incurvados en la punta con a mplia vaina oval en la base; lámina ancha y ampliamente incurvada formando un ápice cuculado; margen entero; parte superior de la vaina con un borde hialino; nervio que termina en la punta o es escurrente en corto apículo; células marginales en el medio de la lámina pequeñas y con pared gruesa; 30 lamelas de 150-190 nm. en el centro de la lámina y compuestas de 6-10 filas de células, las marginales lisas, oval cónicas y fuertemente engrosadas en la punta. 
lageniformes terminadas en una gran papila que produce un aspecto crenado. Gametófito masculino con filidios más cortos y más fuertemente aristados. Filidios periqueciales más largos, el interno fino, blanquecino, sin lamelas y con una larga arista. Seta rojiza de hasta $3 \mathrm{~cm}$. Urna marrón rectangular ovoide prismática con 4 ángulos bien marcados, erecta, inclinada cuando seca, cubierta por la caliptra; hipófisis visible; células del exotecio más o menos cuadradas de pared fina, mamilosas; opérculo con rostro largo; membrana basal del perístoma alta, casi la $1 / 2$ de la longitud del mismo. Esporas a marillo-verdosas lisas de 10-12 nm. Esporófito en verano. Densos o laxos céspedes verde marrón, en suelos silíceos, pedregosos, secos, a veces en suelos arenosos calcáreos desde el piso inferior hasta el alpino y nival. M.T.: Aran; Guells del Jueu, en el abetal. Pirineo Central (Lleida). Leg. A. Alvarez, det. C. Casas, 12-VII-1978 (BC).

Xerófila, terrícola, fotófila, calcífuga tolerante.

Cosmopolita.

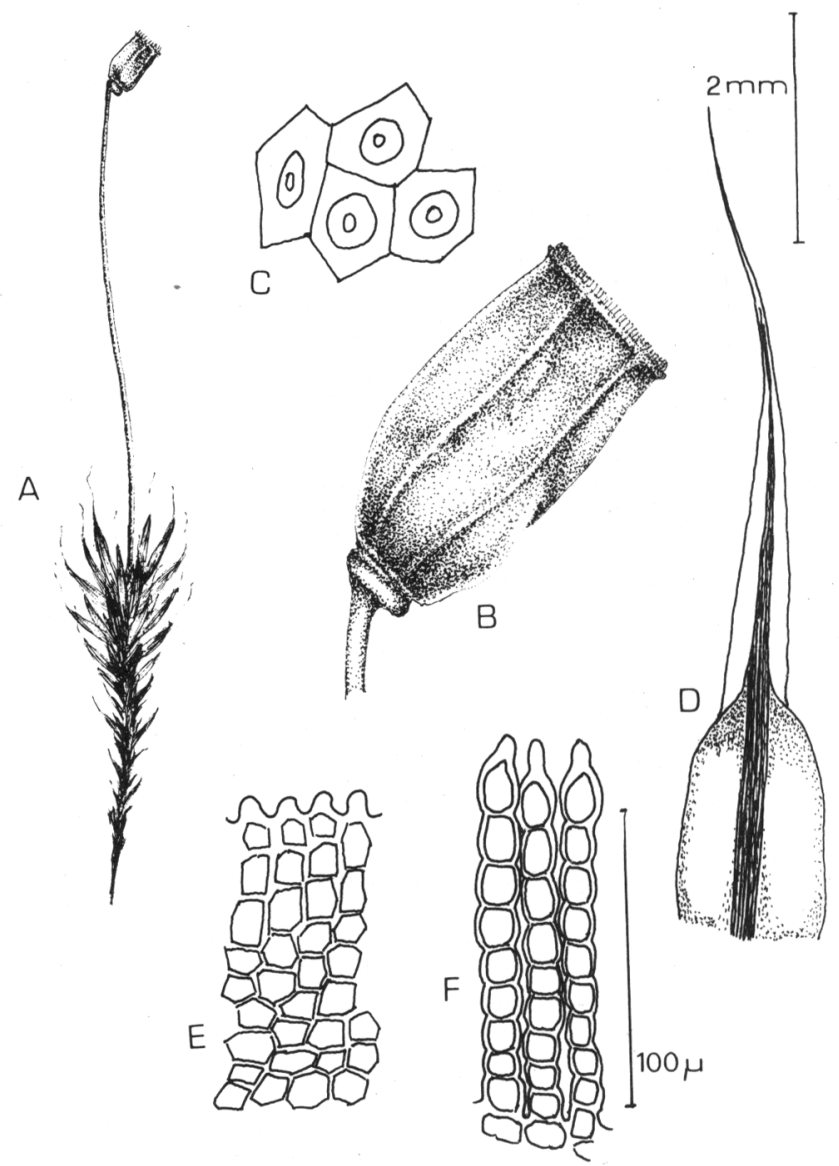

Fig. 7.-Polytrichum piliferum Hedw. A, planta (x 2). B, urna (x 6). C, células del exotecio. D, filidio. E, lamela. F, sección de la lamela. 
var. hoppei (Hornsch) Rbh.

Caulidios más cortos, pelo del filidio más largo, urna casi cúbica. Los filidios perigoniales tienen un color rojo ladrillo o anaranjado y comunican una colaración perceptible en los sitios donde crece. Cortés (1953) al examinar unas muestras de $P$. piliferum de Guadalupe observa que los pelos de la caliptra presentan un color rosa vivo como los de la var. boppei procedentes de Wiklow pero cree que las diferencias en la coloración se deben al estado de madurez. Hemos observado que los ejemplares de $P$. piliferum que poseemos del piso alpino son pequeños y sus caracteres corresponden a los descritos para esta variedad, pero el color de las caliptras es muy variable, pensamos que se trata de una forma de altura paralela a la var. alpinum del $P$. juniperinum.

\section{Distribrución en España}

Galicia.-Común (Lui. 1918). PO: Vigo (Seoan. in Cas. 1972; Ade et al. 1942). LU: Lugo (Lge. in Col. 1889; Run. 1964). C; Ordenes (Run. 1964).

Asturias.-O: Asturias (Lev. et al. 1880). Cañada de Bandujo; Puerto Ventana (Sim. 1973). Brañas de Abajo; Leitariegos (Dur. in Sim. 1977). Valle de Naviego (Dur. in Gay 1836).

País Vasco.-SS: Igaratza (Ser. 1946). Monte Jaizquíbel; Plazaola; Anzuola; Zumárraga (V. All. 1955). BI: Elorrio (V. All. et al. 1946).

Navarra.-NA; Sierra de Alaiz (Fue. et al. 1975). Puerto de Ibañeta (Fue. in Cas. 1972). Sierra de Leyre (Cas. et al. 1977b). Puerto de Velate; Vertiz; Donamaría (V. All. 1955). Burguete; Ronesvalles (Née in Col. 1889). Urquidi (Lac. 1885). Aragón.-HU: Puerto de Benasque (Zet. 1865). Bielsa (Cas. 1961). Panticosa (Zub. 1921). Z: Moncayo (Ton. 1903). TE: Orihuela del Tremedal (Cas. et al. 1977a).

Catalunya.-Aran (Ler. in V. All. et al. 1962b). GE: Maçanet de la Selva (Viv. 1947). Sant Llorenç de la Muga (Bru. et al. 1974). Sant Pere de Roda (Cas. 1958). Núria (Cas. 1952; V. All. et al. 1976; Bra. 1948). B: Montseny (Cas. 1959-60). La Roca (Cas. et al. 1956). T: Serra de Prades (V. All. et al. 1962c).

Andorra.-Casamanya (Bra. 1948). Incles (Cas. 1951b). Coll d'en Valira (Bra. 1948).

León.-LE: Villafranca del Bierzo (Lge. in Col. 1889). SA: La Alberca (Cor. 1951). Tejares (Lui. 1924).

Castilla la Vieja.-SO: Entre Cidones y Vinuesa, Puerto de Santa Inés; La Poveda; Riaza (Cas. 1975a). LO: Rioja (Poz. in Col. 1889). Ortigosa (Ton. 1906). El Rasillo (Zub. 1921). San Millán de la Cogolla (Lag. in Col. 1889). SG: San Ildefonso (Quer in Col. 1889). S: Picos de Europa (Lev. et al. 1880). PA: Peña Labra (Cas. 1953). BU: Soncillana (Fol. et al. 1917).

Castilla la Nueva.-M: Guadarrama (Riv. G. in Cor. 1951; Casar. et al. 1912). Colmenar Viejo (Lge. in Col. 1889). Paular (Née in Col. 1889). TO: Marrupe (V. All. et al. 1946).

Extremadura.-CC: Guadalupe; Puerto de Santa Clara (Cor. 1953).

Andalucía.-AL: Sierra del Cabo de Gata (V. All. et al. 1958). J: Despeñaperros (V. All. et al. 1958). GR: Sierra Nevada (Zaf. et al. 1974). Sierra de Agibe (Clem. in Col. 1889). SE: Cazalla de la Sierra (Gon. 1883). 
var. hoppei (Hornsch.) Rbh.

Castilla la Vieja.-AV: Herradón (Casar. 1915).

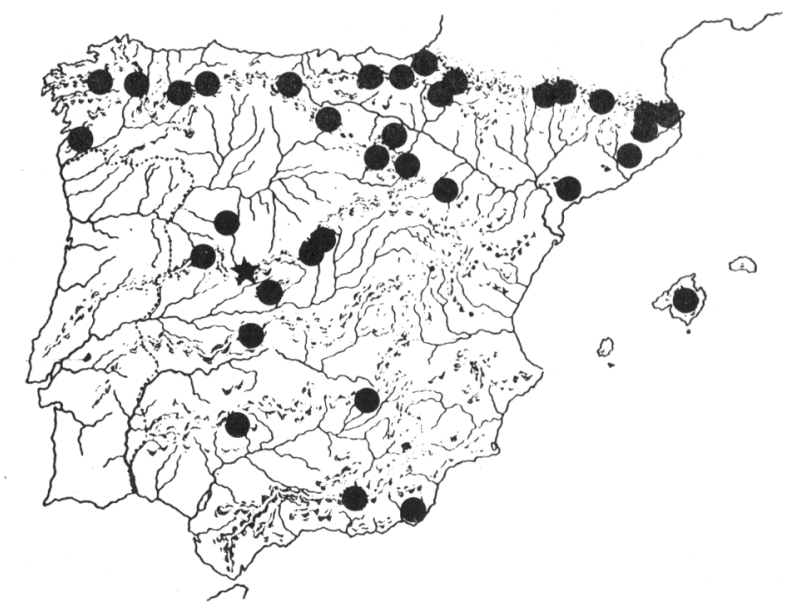

Polytrichum pilifertum Hedw. Distribución conocida en España Ł var. hoppei (Hornsch.) Rbh

Polytrichum juniperinum Hedw. Sp. Mus. 1801. juniperinum Willd.

Gametófito de 2-6 hasta $10-12 \mathrm{~cm}$. Caulidios simples sin tomento rizoidal en la base o con un denso tomento blanquecino rojizo. Filidios inferiores escuamiformes a veces prolongados en una arista larga, los superiores erecto-patentes en estado húmedo, erectos o imbricados en seco, linear lanceolados de 6-8-10 mm. con la parte basal oval erecta con un borde hialino en el ángulo superior; lámina de margen entero incurvada por encima de las lamelas; células de la parte superior rectangulares, transversas, en la base de la vaina alargadas rectangulares; nervio con el dorso dentado, prolongado en una larga arista dentada, marrón; 35-40 lamelas hasta de $100 \mathrm{~nm}$. compuestas de 5-8 filas de células con marginal engrosada en el apice tormando un margen a veces crenulado. Filidios periqueciales más largos, con larga arista y borde blanco membranoso. Caulidios masculinos más débiles y con hojas más cortas. Seta de $4-5 \mathrm{~cm}$. rojiza. Urna marrón erecta a veces inclinada, tetragonal oblonga de $4 \mathrm{~mm}$. con hipófisis visible; opérculo plano con corto apículo; células de exotecio cuadrangulares o hexagonales, mamilosas con poro linealy grandes estomas en el surco. Caliptra blanquecina con la punta rojiza que cubre completamente la urna; perístoma pálido más alto que la membrana basal; epifragma entero. Esporas lisas $10 \mathrm{~nm}$. Esporófito en verano.

Crece en céspedes laxos sobre suelos secos o húmedos a veces mojados, brezales pedregosos, bosques, paredes, sobre tocones de árboles en las zonas bajas hasta el piso alpino. M.T.: Güells del Jueu, Aran (Lleida) $1.450 \mathrm{~m}$. Leg. A. Alvarez, det. C. Casas, 12-VII-1978. (BC).

Xerotila, mesófila, fotófila, terrícola, calcífuga.

Cosmopolita. 
var. alpinum Schimp. Syn. Mus. Europ. 1860

Caulidios más cortos, hasta $1,5 \mathrm{~cm}$, filidios, $4,5-5 \mathrm{~mm}$, punta roja lisa, seta $1,5-2,5$ $\mathrm{cm}$, urna prismática cúbica, opérculo deprimido con a pículo corto, dientes del perístoma cortos y pálidos; caliptra a veces blanca nivea.

Examinados los ejemplares recolectados en las laderas secas entre los claros del prado alpino en las vertientes del Veleta en Sierra Nevada, presentan las características señaladas por Schimper. En los ejemplares que proceden de los prados alpinos del Pirineo, sobre los $2.000 \mathrm{~m}$, no se aprecian diferencias esenciales con los de Sierra Nevada y se considera que pertenecen a esta variedad. Pero estos caracteres son muy variables, incluso el color de la caliptra que puede llegar a ser blanca, de tal manera que si se dispone de mucho material no es posible una exacta delimitación. Piso alpino y nival.

Xerófila, fotófila, calcífuga.

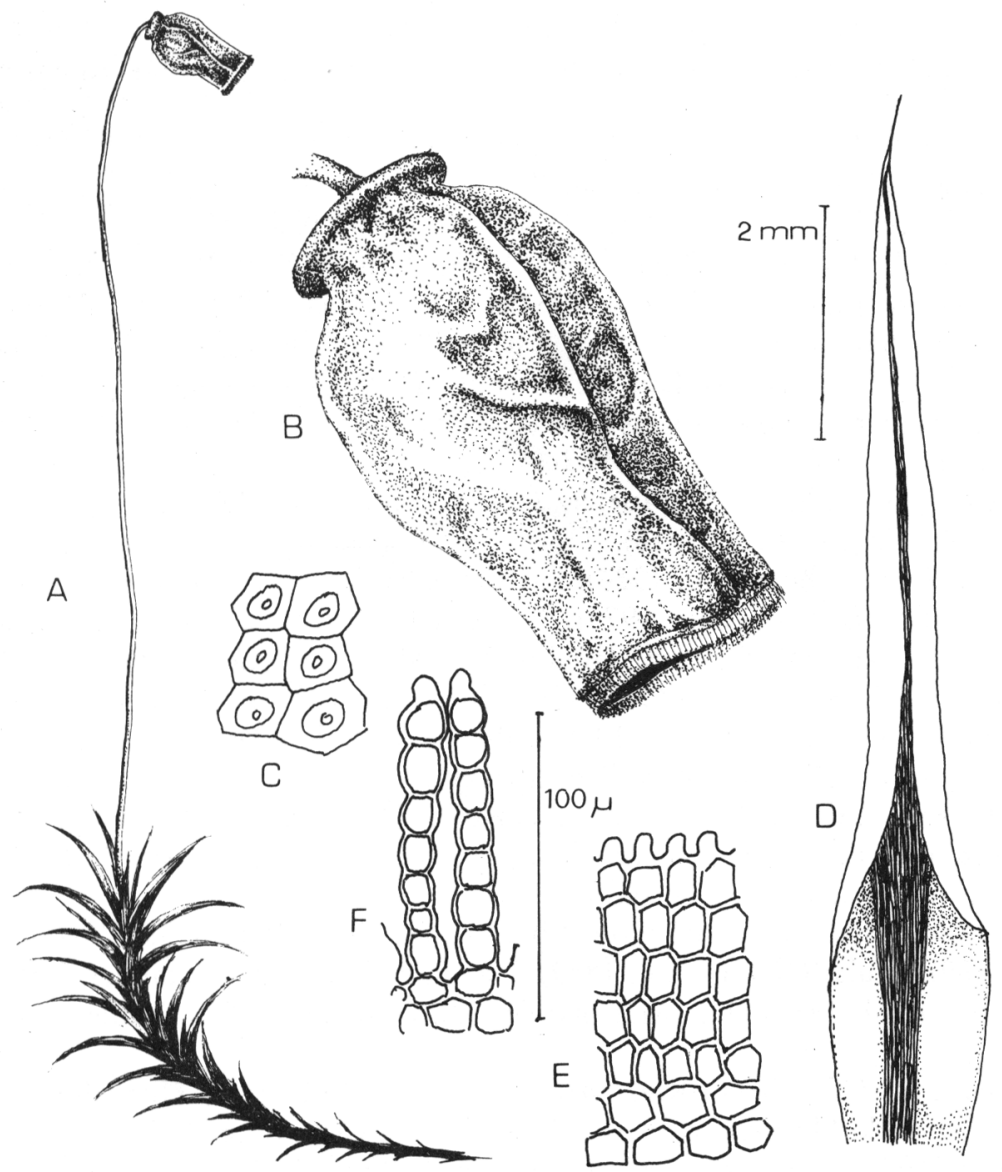

Fig. 8.-Polytrichum juniperinum Hedw. A, planta (x 2). B, urna (x 12). C, células del exotecio. $\mathrm{D}$, filidio, E, lamela. F, sección de la lamela. 
ssp. strictum (Brid.) Nyl. et Sael.

(var. gracilis Wg., P. strictum Menz ex Brid.)

Caulidio fuertemente tomentoso desde la base. Filidios más cortos y erectos, urnas más cortas que en $P$. juniperinum. Crece entre los Sphagnum al borde de los lagos en el piso subalpino y alpino.

\section{Distribución en España}

Galicia.-OR: Orense (Lev. et al. 1880). C: Santiago (Tex. 1869). Santiago; Ordenes (Run. 1964).

Asturias.-O: En las montañas (Lev. 1880). Páramo; Monte de la Puerca; Monte Grande; La Focella (Sim. 1973). Cueto de Arbás (Durieu in Sim. 1977).

País Vasco.-SS: Monte Jaizquíbel; Plazaola (V. All. 1955). BI: Lequeitio (V. All. 1955).

Navarra.-NA: Sierra de Alaiz (Fue 1975). Roncesvalles; Burguete (Née in Col. 1889). Vertiz; Burguete; Puerto de Velate (V. All. 1955). Mayurqueta (Lac. 1885).

Aragón.-HU: Bielsa (Cor. 1951; Camp. y Los. in Col. 1889). TE: Orihuela; Bronchales; Monterde (Cas. et al. 1977a).

Andorra.-Coll d'en Valira (Bra. 1948). Ensagents (Cas. 1951b).

Catalunya.-L: Port de la Picada (Bra. 1948). Vall de Sant Nicolau (Ser. 1956).

Port de la Bonaigua (V. All. et al. 1962b). GE: Arbúcies (Bra. 1948). Núria (Bra. 1948; Vay. 1882; V. All. et al. 1976; Cas. 1952). La Sellera (Cod. 1908). Maçanet de la Selva (Viv. 1947). St. Pere de Roda (Cas. 1958). B: Bruguers (Cas. 1951a). Rasos de Paguera (Cas. 1954). La Roca (Cas. et al. 1956). Montseny (Cas. 1959-60). Serra de Prades (V. All. et al. 1962c).

Islas Baleares.-Puig de Maçanella; Coma Freda (Slo. 1967).

León.-SA: Común (Lui. 1918). Tejares; Ledesma; Olmedo; Ciudad Rodrigo; Sierra de Francia; Béjar (Lui 1924). Las Batuecas; La Alberca (Cor 1951). LE: Pinar de Lillo (Izco in Cas. 1975). Ponferrada; Busdongo (P. All. 1928c).

Castilla la Vieja.-AV: Sierra de Gredos (Riv. Mat. 1897; Cor. 1951). BU: Duruelo; Pineda de la Sierra (Font Q. in Cas. 1975a). Soncillana (Fol. et al. 1917). SO: Entre Cidones y Vinuesa (Cas. 1975a). PA: Alar del Rey (V. All. et al. 1956). Pozo de Curavacas (Cas. 1953). S: Peñalabra (Cas. 1953). Peñas de Trilleruelo (Salc. in Col. 1889). LO: San Millán de la Cogolla (Leg. in Col. 1889). Rioja (Poz. in Col. 1889). Ortigosa de Cameros (Ton. 1906) SG: San Ildefonso (Rodr. in Col. 1889). Entre Riaza y Ayllón (Cas. 1975a).

Castilla la Nueva.-M: Somosierra (Lop. in Cas. 1975c). Colmenar Viejo (Leg. in Col. 1889). Paular (Née in Col. 1889). Escorial; Cercedilla; Matabuena; Miraflores (Casar et al. 1912). TO: Marrupe (V. All. et al. 1946). CU: Valdemeca (Rol. 1897).

Extremadura.-CC: Gata (Riv. Mat. 1897). Las Villuercas; Guadalupe (Cor. 1951). Baños de Montemayor; Alia; Puerto Santa Clara (Cor. 1053). Pico de Jálama (Lui. 1924). BA: Medina de las Torres (Fru. 1914).

Andalucía.-CA: Peñón del Fraile (V. All. et al. 1945). Sierra del Pinar (V. All. et al. 1946). GR: Sierra Nevada (War. 1911; Clem. in Col. 1889; Zaf. et al. 1974). MA: Cartajima (V. All. et al. 1946). 
var. alpinum Schimp. Syn. Mus. Europ. 1860

Castilla la Vieja.-Picos de Europa (Lev. et al. 1880).

Andalucía.-GR: Laguna de las Yeguas (V. All. et al. 1956). Campos de Otero (Varo in Cas. 1975b). Veleta (Schimp. 1860; Casar. 1915; Ther. 1932).

ssp. strictum (Brid.) Nyl. et Sael.

Asturias.-O: Leitariegos (P. All. 1934).

Aragón.-HU: Panticosa (Zub. 1921).

Catalunya.-L: Boí (Cas. 1972).

León.-LE: San Isidro (P. All. 1934).

Castilla la Vieja.-S: Peñalabra (Cas. 1953).

Andorra.-Envalira (Cas. 1951b).

Según Casares (1915) haber señalado en España P. strictum Banks. obedece a una confusión de nombres entre la var. alpinum Schimp. de $P$. juniperinum y el $P$. alpestre Hoppe que, según el mismo Casares, es realmente variedad de P. strictum. Según Index Muscorum, $P$. alpestre Hoppe es la var. affine Funck. de juniperinum. Nuevas recolecciones han puesto de manifiesto que la ssp. strictum existe en España y se conocen actualmente variạs localidades en el norte.

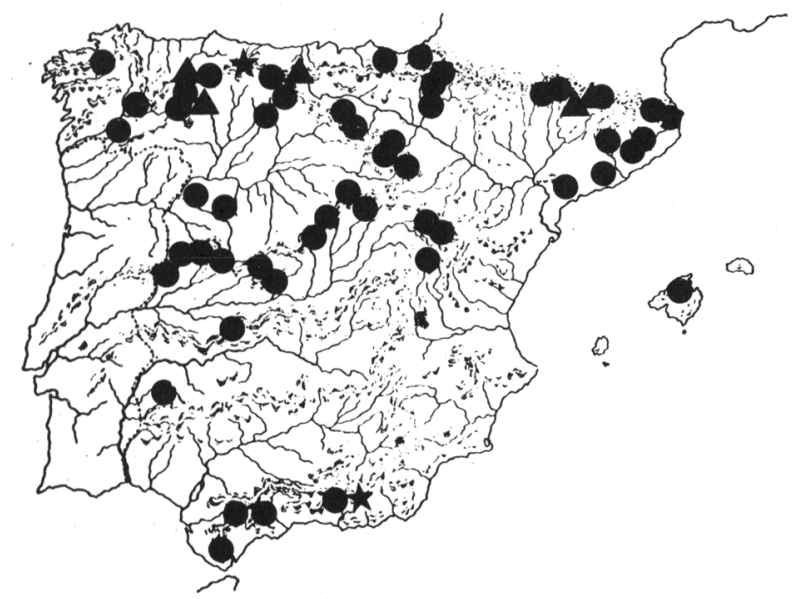

Polytrichum juniperinum Hedw. Distribución conocida en España. \var. alpinum Schimp. « sp. strictum (Brid.) Nyl. et Sael.

POGONATUM P. Beauv., Mag. Enc., 1804

Dioco. Gametófito pequeño o robusto. Caulidios simples o ramificados. Filidios patentes o erecto-patentes de base ancha, brillante, más o menos membranosa que se estrecha formando una lámina linear ovalada o linear lanceolada; margen de la parte superior de la lámina más o menos dentado; nervio ancho en la parte 
superior, mal delimitado, estrecho y más distinto en la base, parte ventral cubierta de numerosas lamelas longitudinales que ocupan la mayor parte de la anchura del filidio; células de la parte superior de la lámina más o menos isodiamétricas, alargadas en la base. Seta larga, lisa y fuerte. Urna recta o poco inclinada que varía de esférica o casi a ovado-alargada sin pliegues externos y sin hipófisis ni estomas, de sección transversal circular; células del exotecio densas, mamilosas; dientes del perístoma pálidas con una línea central oscura, marrón amarillento, membrana basal corta o alta; opérculo cónico redondeado, rostrado; caliptra cubierta de numerosos pelos largos que llegan casi hasta la base de la urna.

1. Caulidio corto simple. Filidios de unos $4 \mathrm{~mm}$.; acumen ancho con el nervio no excurrente; células marginales de las lamelas lisas o casi.

1. Caulidio alto ramificado, filidios de 6 a $9 \mathrm{~mm}$.; lámina aguda con el nervio excurrente; lamelas con la célula marginal papilosa.

3 P. urnigerum

2. Filidio dentado en el tercio superior con dientes redondeados y superficiales. Urna subglobosa con las células del exotecio lisas o finamente papilosas, 30-40 lamelas.

1 P. nanum

2. Filidio dentado desde la base con dientes y profundos. Urna oblongo-cilíndrica con las células del exotecio con mamilas anchas y cónicas, 46-60 lamelas.

2 P. aloides

Pogonatum nanum (Hedw.) P. Beauv. Prodr., 1805

Gametófito verde o marrón de $4-10 \mathrm{~mm}$. que se desarrolla sobre un protonema persistente. Caulidios erectos simples. Filidios erecto-patentes en estado húmedo, erectos en estado seco, de 3-5 mm.; lámina oval-lanceolada, obtusamente acuminada; margen del tercio superior con dientes obtusos y cortos formados generalmente por una sola célula; lamelas formadas por 4-6 filas de células más o menos homogéneas de paredes delgadas, la marginal con el borde liso; células de la parte superior de la lámina cuadrado-redondeadas de 12-16 nm. que se alargan gradualmente pasando a rectangulares 2 ó 3 veces más largas que anchas. Seta tına, flexuosa, de color marrón rojizo de 10-30 mm., girando ligeramente hacia la de- recha en la parte superior. Urna corta oval o casi esférica recta o inclinada, de boca ancha cuando está madura de 1-2,5 mm. y 1,5 mm. de diámetro; células del exotecio no mamilosas pero si finamente papilosas; perístoma de 32 dientes casi lisos hialinos con una banda estrecha marrón-rojiza en el centro, membrana basal corta hialina marrón rojiza en la base de unas $40 \mathrm{~nm}$; opérculo rostrado con pico oblicuo. Esporas de 19-26 nm. Esporófito en otoño o invierno.

Césped más o menos denso de color verde oscuro, sobre suelo arenoso, taludes, claros de bosque, borde de caminos. M.T.: Sta. Fe del Montseny. $1.100 \mathrm{~m}$. Talud sombreado, 16.2.57, leg. et det. C. Casas (BC).

Mesófila, esciófila, terrícola, calcífuga.

Subatlántica con disyunción austral. 
var. longisetum (Hampe) Br. eur.

Filidios más largos y estrechos. Seta más larga, pudiendo alcanzar más de $5 \mathrm{~cm}$. de longitud. Urna oval-cilíndrica finamente papilosa; dientes del perístoma muy irregulares.

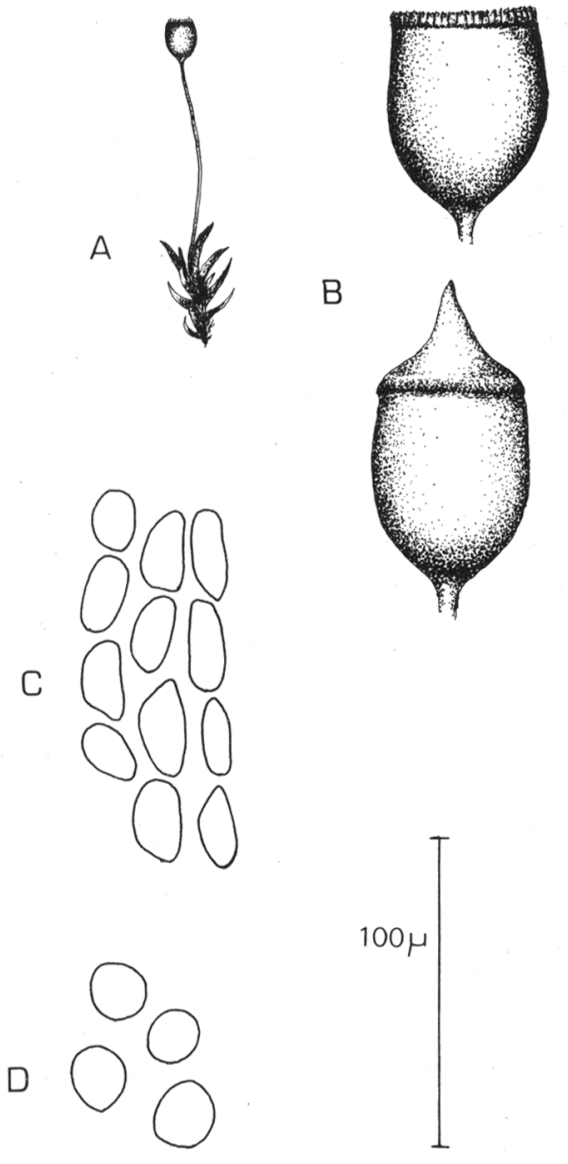

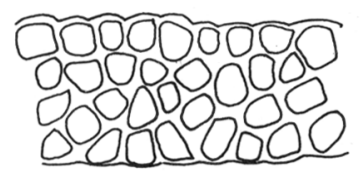

$\mathrm{F}$

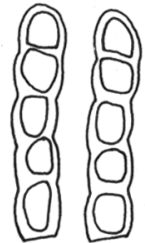

G
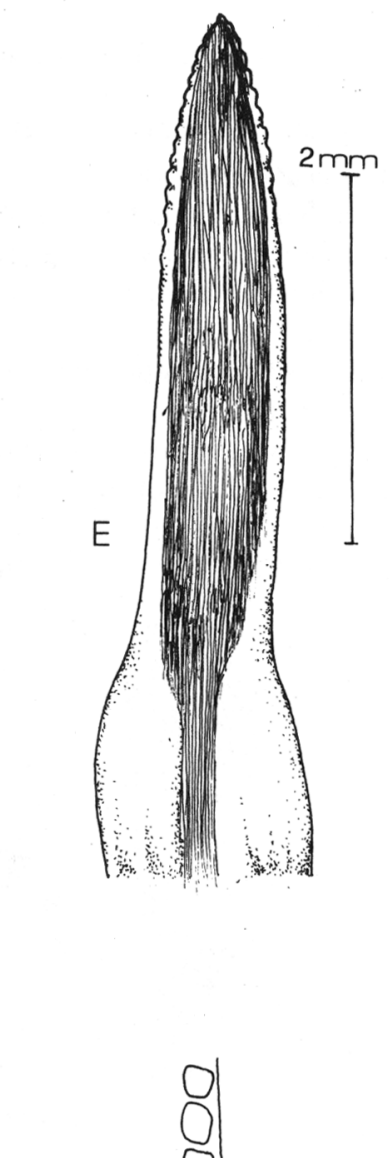

Fig. 9.- Pogonatum nanum (Hedw.) P. Beauv. A, planta (x 2). B, urna con y sin opérculo (x 12). C, células del exotecio. D, esporas, E, filidio, F, lamela, G, sección de la lamela. H, margen del filidio cerca del ápice. 
Distribución en España

Galicia.-OR: Cercanías de la capital (Casar. 1915). Orense (Lui 1918).

PO: Campolongo (Lui. 1918).

Asturias.-O: Arbás (Lag. in Amo 1870).

País Vasco.-SS: Monte Jaizquíbel (V. All. 1955).

Navarra.-NA: Burguete (Nee in Amo 1870). Vértiz (Lac. 1885).

Catalunya.-L: Estaon (Leg. Casas BCF). B: Sta. Fe del Montseny (C. Casas $\mathrm{BCF})$.

León: SA: Tejares, Montalbo; Olmedo; Sierra de San Jorge; Lumbrales; Perosín; Villas Rubias; Sierra de Jálama (Lui. 1924).

Castilla la Vieja.-AV: Gredos (Cil. 1945).

Castilla la Nueva.-M: Becerril (Lag. in Amo 1870). Sierra de Guadarra (Casar. 1915). San Rafael; Cercedilla; Navacerrada; Miraflores; Matabuena (Casar. et al. 1912).

Extremadura.-Guadalupe; entre el Puerto de Santa Clara y San Martín de Trevejo (Cor. 1953).

Andalucía.-GR: Barranco de Trevélez (Clem. in Amo 1870).

var. longisetum (Hampe) Br. eur.

Galicia.-OR: Cercanías de la capital (Casar. 1915). Orense (Lui 1918).

Andalucía.-CA: Valle de la Miel; Peñón del Fraile (V. All. et al. 1946).

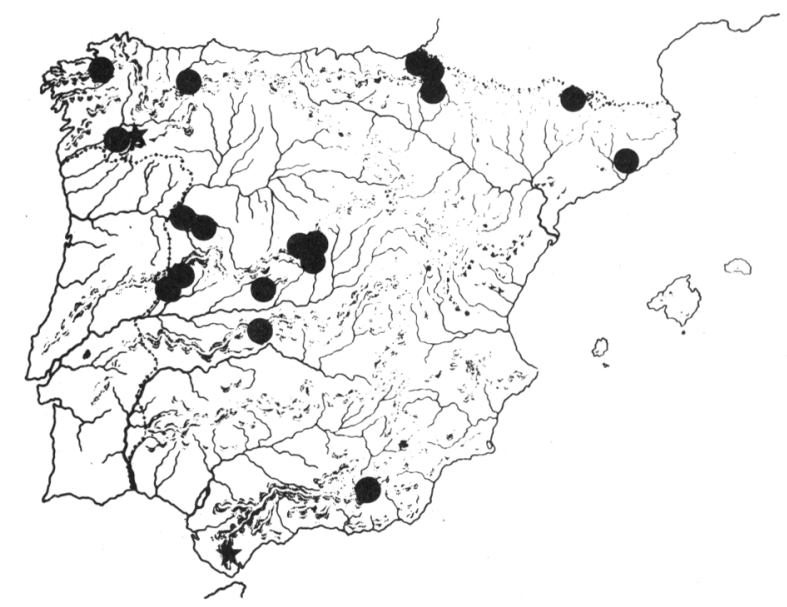

Pogonatum nanum (Hedw.) P. Beauv. Distribución conocida en Españ.ı Ł ar. longisetum (Hampe) Br. Eur.

Pogonatum aloides (Hedw.) P. Beauv., Prod., 1805 (Polytrichum aloides Hedw.)

Gametófito verde o marrón de $5-20 \mathrm{~mm}$. que se origina a partir de un protonema persistente. Caulidios erectos, simples algunas veces ramificados. Filidios inferiores escuamiformes, los superiores de 4-7 mm., extendidos o erecto-patentes en es- 
tado húmedo, erectos o incurvados en estado seco; base envainadora que continua bruscamente en una lámina oval-lanceolada, más o menos acuminada; margen plano densamente denticulado desde la base de la lámina hasta el ápice, los dientes formados por varias células; células de la parte superior de la lámina densas más o menos isodiamétricas de $12-15 \mathrm{~nm}$ finamente papilosas en el dorso, las de la base rectangulares de 2-4 veces más largas que anchas, las marginales lineares agudas de 8-10 veces más largas que anchas; lamelas numerosas, de 40-60, formadas por 4-5 filas de células más o menos homogéneas, de paredes finas y lisas. Filidios periqueciales internos de base hialina que continua gradualmente en una lámina anchamente acuminada.

Seta larga de $15-35 \mathrm{~mm}$. de color púrpura. Urna oval-cilíndrica, erecta o poco oblicua de 1,5-3,5 mm. de largo y $1 \mathrm{~mm}$. de diámetro; células del exotecio mamilosas; perístoma fino y densamente papiloso formado por 32 dientes marrón rojizo con el borde hialino, cortos, me mbrana basal de unas $80 \mathrm{~nm}$. de alto; opérculo rostrado con el pico recto; columela tetrangular. Esporas de 14-19 nm. lisas o casi. Esporófito en otoño e invierno. Céspedes verde oscuro o marrón, más o menos densos, so-

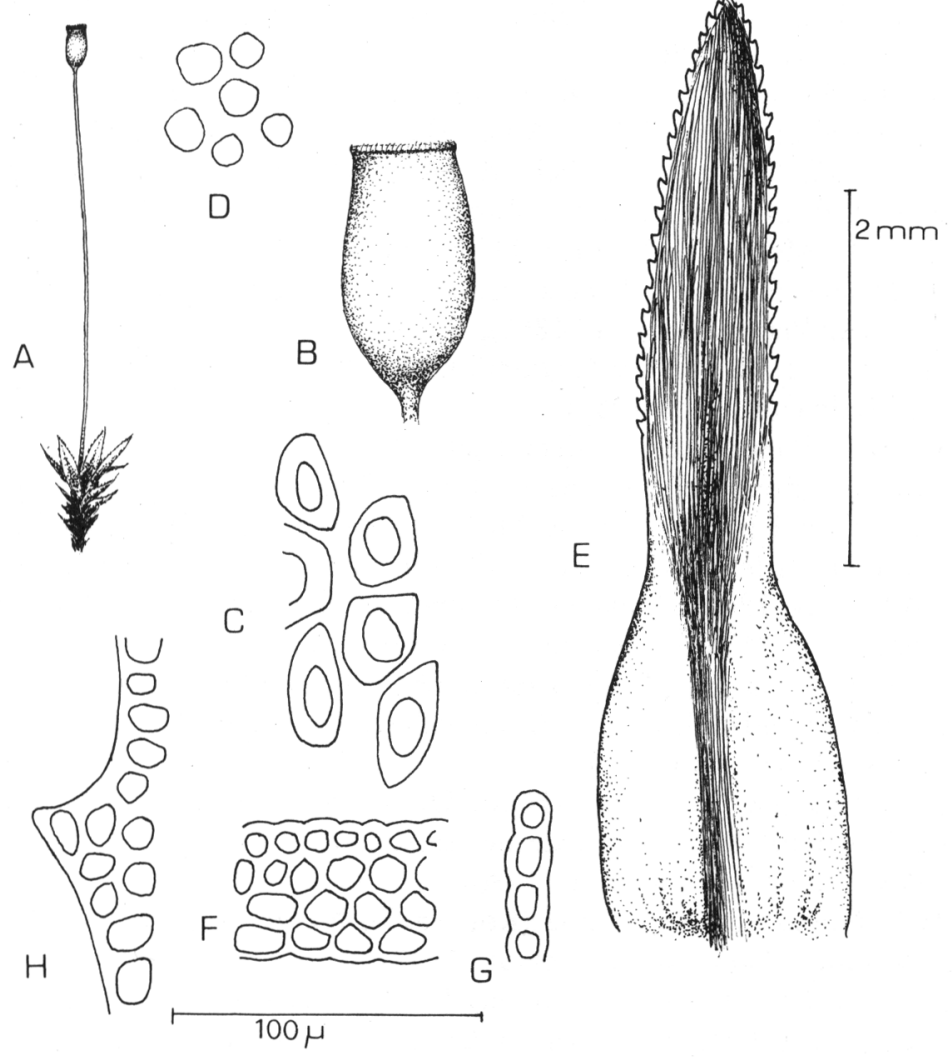

Fig. 10.-Pogonatum aloides (Hedw.) P. beauv. A, planta (x 2). B, urna (x 12). C, células del exotecio. D, esporas. E, filidio. F, lamela. G, sección de la lamela. $\mathrm{H}$, margen del filidio. 
bre suelo arenoso y taludes silíceos en el piso montano. M.T.: Núria. Taludes al borde de los caminos. Agosto 1942, leg. et det. C. Casas (BC).

Mesófila, esciófila, terrícola, calcífuga preferente.

Circumboreal; en Europa, subatlántica.

var. minimum (Crom.) Mol., Jabresb. Naturw. Ver. Passau, 1875

Filidios menos dentados. Seta más corta de 6-7 mm. Urna obovoide, más corta y atenuada en la base. Dientes del perístoma más largos con el borde hialino más anchos, membrana basal de unas $40 \mathrm{~nm}$.

Díficil de distinguir de $P$. nanum, difieren en las células del exotecio que son mamilosas, en la columela tetrangular, en el tamaño de las esporas y los dientes del margen de los filidios son más agudos.

Distribución en España

Galicia.-Común en toda Galicia (Lui. 1918; Casar. 1915). C: Santiago de Compostela (Ade et al. 1942). El Ferrol (Lag. in Amo 1870). La Graña (Mul. 1854). PO: Vigo, falda del monte Galliñeiro (Cas. 1972). Valle del Sil (P. All. 1928c). OR: Meirama (Run. 1964).

Asturias.-O: Estrella (Lev. et al. 1880). Páramo; Monte de la Puerca; Monte Grande; Ferreirúa (Sim. 1973). Arbás (Lag. in Amo 1870).

País Vasco.-SS: Monte Jaizquíbel; Monte Haya; Monte Uria; Monte Urguel; Aránzazu; Aizpurrucho; Plazaola; Zarauz; Orio; Alegría de Orio; Rentería (V. All. 1955). BI: Montes de Vizcaya (Herb. Durieu in Sim. 1977). Monte Sóllube; Elorrio; Monte Pagasari; Plencia; Cabo Machichaco (V. All. 1955).

Navarra.-NA: Viataqueta (Lac. 1885). Puerto de Ibañeta (Fuer. in Cas. 1975b). Arauquite (Cas. et al. 1977b). Burguete; Véritz; Puerto de Velate; Donamaría; Endarlanga; Isaloa (V. All. 1955).

Aragón.-HU: Puerto de la Glera (Zet. 1865).

Catalunya.-L: Bosc de Virós (Leg. Casas BCF). B: Campins; Mosqueroles; Montseny; Coll Formic; Turó de Morou; Santa Fe del Montseny; Riells (Cas. 1959-60). Font de les Closes (Viv. 1947). GE: Montseny (Casar. 1915; Cas. 195960; V. All. et al. 1946). Arbúcies; Viladrau; Sant Marcal (Cas. 1959-60). Núria (Cas. 1952; Vay. 1882). Maçanet de la Selva (Viv. 1947).

León.-LE: Valle del Sil (P. All. 1928c). SA: Tejares; Olmedo; Hinojosa de Duero; Bermellar; Ciudad Rodrigo; El Payo; Sierra de Jálama; Soto de San Martín; Béjar; El Castañar (Lui 1924).

Castilla la Vieja.-S: Santander (Herb. Durieu Sim. 1977). SO: Laguna Negra; pista de Covaleda junto al puente del río Queros (Cas. 1975a). SG: La Granja (Car. 1951). San Ildefonso (Lev. 1880).

Castilla la Nueva.-M: Cercedilla (Rol. 1897). Navacerrada (Lev. in Col. 1889). Sierra de Guadarrama (Casar. et al. 1912).

Extremadura.-CC: Guadalupe (Cor. 1951). Guadalupe en el Humilladero; Puerto de Santa Clara, entre las provincias de Cáceres y Salamanca; Yuste (Cor. 1953). Baños de Montemayor (Cil. 1945). Soto de San Martín (Lui 1924). Andalucía.-CA: Algeciras, valle del Guadalmesi; Peñón del Fraile (V. All. et al. 1945). Valle del Infierno (V. All. et al. 1945; Rich. 1932). SE: San Nicolás del 
Puerto; Guadalcanal (Gon. 1883). GR: Valle del Genil (Hoh. 1895). Sierra Nevada, en la hoya de la Mora (Var. in Cas. 1975c).

var. minimum (Crom.) Mol. (= var.defluens Brid.)

Galicia.-C: Vilaboa (Casar. 1915). El Ferrol (Lag. in Amo 1870). Santiago de Compostela (Ade et al. 1942). P: Campolongo (Lui 1918). Vigo (Cas. 1972). Andalucía.-GR: Sierra Nevada, Valle del Genil (Geh. 1874).

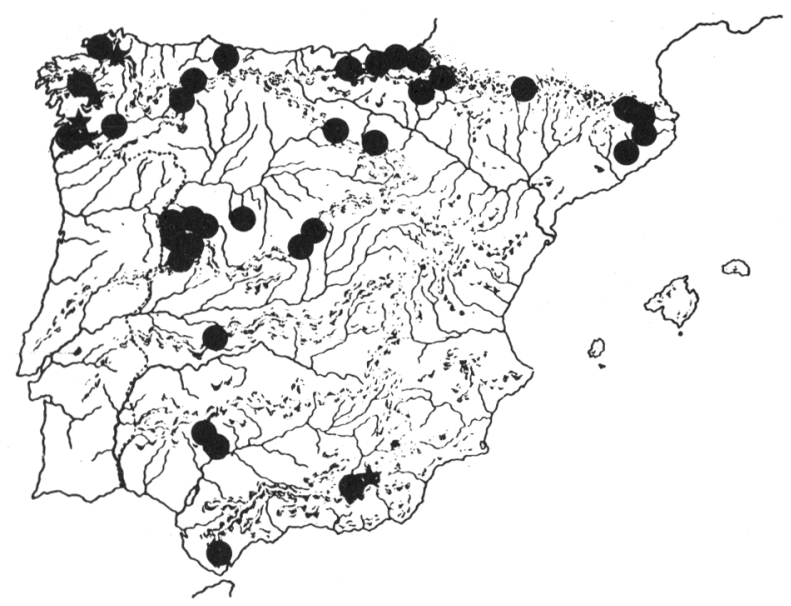

Pogonatum aloides (Hedw.) P. Beauv. Distribución conocida en España. $\star$ var. minimum (Crom.) Mol.

Pogonatum urnigerum (Hedw.) P. Beauv. Prodr., 1805

Polytrichum urnigerum L.

Gametófito glauco en la parte superior, marrón ferruginoso en la parte inferior de 4-10 cm., desarrollado a partir de un rizoma subterráneo. Caulidios erectos ramificados. Filidios inferiores escuamiformes, apiculados, los medios y superiores mayores de 6-9 mm. rígidos apretados contra el tallo, imbricados, erectos o poco incurvados cuando están secos, extendidos o incluso recurvados en estado húmedo; de base envainadora corta que continua en una lámina lanceolada-linear, aguda; margen fuertemente dentado desde el ápice hasta cerca de la base; células de la parte superior de 13-19 nm, cuadrado-redondeadas, densas, muy alargadas en la base; nervio excurente en una punta corta fuertemente denticulada; 40-50 lamelas cuya sección transversal muestra de 4-6 células, la marginal más ancha que las restantes, redondeada, de color marrón amarillento, papilosa, las restantes lisas, verdes. Filidios periqueciales externos más dilatados en la base, los internos alargados y más brevemente acuminados. Seta larga, rojo-amarillenta, de $2-5 \mathrm{~cm}$. Urna cilíndrica erecta o muy ligeramente inclinada simétrica, de color marrón dorado que pasa a ser marrón en estado maduro; células del exotecio mamilosas; perístoma 
finamente papiloso formado por 32 dientes lineares-ligulados rojizos con la membrana basal alta (alrededor de $120 \mathrm{~nm}$ ); opérculo rostrado con el pico recto; esporas de 10-14 nm, a marillas, finamente papilosas, maduran en invierno. Céspedes más o menos laxos de color glauco en suelo descubierto arenoso, taludes, grietas de las rocas. M.T.: Andorra, Vall del Riu. Julio 1947, leg. Losa y Montserrat, det. C. Casas (BC).

Mesófila, esciófila, terrícola, calcífuga.

Circumboreal, en Europa montano-subatlántica.
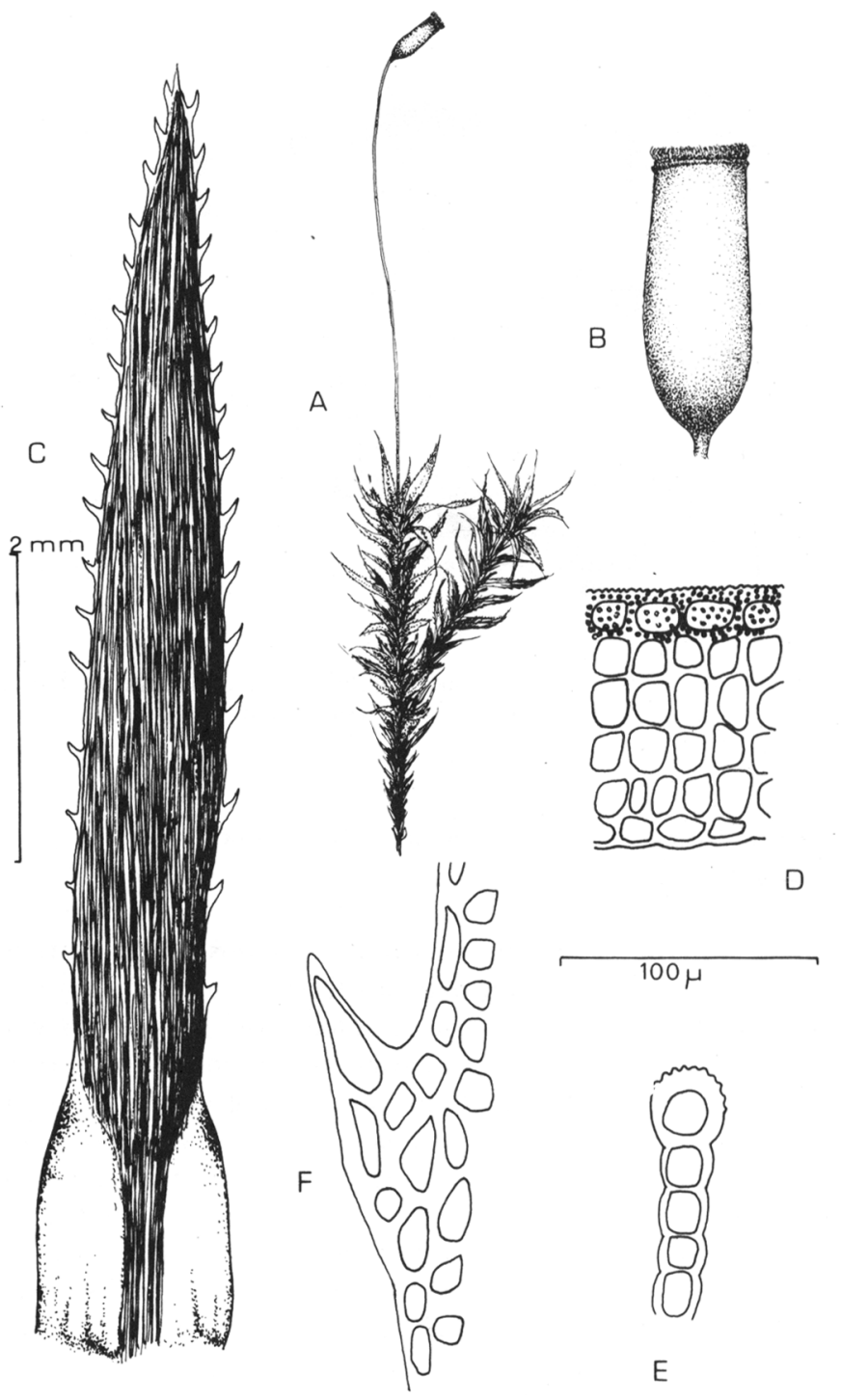

Fig. 11.-Pogonatum urnigerum (Hedw.) P. Beauv. A, planta (x 2). B, urna (x 12). C, filidio. D, lamela. E, sección de la lamela. F, margen del filidio. 
Distribución en España

Galicia.-LU: Fonsagrada (P. All. 1934).).

Asturias.-O: Asturias (Herb. Durieu in Sim. 1977). Valgrande (Lag. in Amo 1870). Valle del río Cares, más arriba de Cain (P. All. 1928b). Puerto Ventana (Sim. in Cas. 1972). Páramo; Monte de la Puerca; Monte Grande; Ferreirúa (Sim. 1973). Faro de Peñas; Avilés (Sim. et al. 1974). Bárcena (Rol. 1897). País Vasco.-SS: Aizpurrucho; Monte Haya (P. All. 1934).

Navarra.-NA: Puerto de Ibañeta (P. All. 1928b). Vertiz (P. All. 1934). Plazaola (V. All. 1955).

Aragón.-HU: Lago Urdiceto (Cas. 1961). Puerto de Benasque (Zet. 1865). Andorra.-Vall del Riu (Cas. 1951b).

Catalunya.-L: Aran (Villiers in Amo 1870). Port de la Bonaigua (V. All. et al. 1962b). Portarró d'Espot (Ser. 1956). B: Sta. Fe del Montseny (V. All. et al. 1946); Cas. 1959-60). GE: Núria (Cas. 1952; V. All. et al. 1976). La Sellera (Cd. 1908).

León.-LE: Puerto de Pontón (P. All. 1934). Llamas (P. All. 1928c).

Castilla la Vieja.-BU: Pista de Covaleda, junto al río Queros (Cas. 1975a). Piedras Luengas (Lev. et al. 1880). SG: La Granja (Cor. 1951).

Castilla la Nueva.-M: Colmenar Viejo (Lag. in Amo 1870).

Andalucía.-SE: Constantina; Cazalla de la Sierra (Gon. 1883).

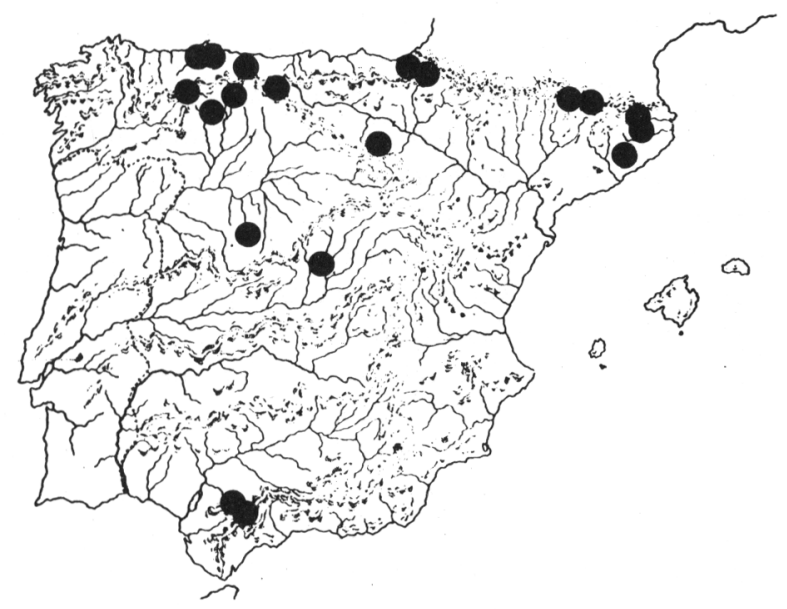

Pogonatum urnigerum (Hedw.) P. Beauv. Distribución conocida en España

\section{ATRICHUM P. Beauv.}

Dioica o monoica. Caulidio simple sobre un rizoma subterráneo. Filidios ligulados-lanceolados moderadamente abrazadores no envainadores, erecto-extendidos, más o menos ondulados en estado húmedo, crispados en estado seco; lámina con la parte superior del dorso espinoso por la proyección de células; margen formado por células estrechas alargadas, fuertemente dentado desde el ápice hasta la mitad de la hoja; células de la lámina más o menos hexagonales en la parte 
superior gradualmente cuadradas y rectangulares hacia la base, lisas o finamente papilosas, nervio fuerte que llega cerca del ápice, en la cara dorsal liso o espinoso, en la ventral con 2-7 lamelas de 1-9 células de alto formado por células más o menos uniformes. Seta larga, lisa, amarilla o roja. Urna lisa cilíndrica recta o curvada cuello indistinto; células del exotecio rectangulares o cuadradas con las paredes verticales más gruesas que las horizontales; en el borde varias filas de células pequeñas coloreadas; estomas ausentes; dientes del peristoma en número de 32, pálidos, con una línea media rojo-amarillenta; opérculo redondo-convexo largamente rostrado; caliptra lisa o espinosa en el ápice.

Filidios ondulados; aproximadamente de $1 \mathrm{~cm}$. de longitud; dentados en los dos tercios superiores; células de la lámina de 20-30 (-38) nm. de ancho; 2-4 (-6) lamelas en la cara ventral de 2-5 filas de células. Urna curvada. Esporas de 20-26 nm. Monoico.

1. A. undulatum

Filidios poco ondulados, pero con la parte superior crispada en el margen; de $1 / 2 \mathrm{~cm}$. de longitud como máximo; dentados en la mitad superior; células de la lámina de menos de $20 \mathrm{~nm}, 10-16(-20) \mathrm{nm}$; 4-7 lamelas de 5-9 filas de células. Esporas de 12-14 nm. Urna erecta o ligeramente inclinada. Dioico.

2. A. angustatum

Atrichum undulatum (Hedw.) P. Beauv., Prodr. 42, 1805

(= Catharinea undulata (L.) Web. et Mohr.)

Generalmente monoico. Gametófito de $2-5 \mathrm{~cm}$. Caulidio erecto, simple o furcado. Filidios inferiores pequeños escuamiformes, los superiores ligulado-lanceolados de 7-9 mm. de largo fuertemente ondulados transversalmente en la mitad superior, crispados o incurvados en seco, húmedos, flexuoso-patentes, acuminados, más o menos decurrentes sin estrecharse en la inserción con el tallo, el envés de la lámina, especialmente en la parte superior cerca del ápice, es áspera con células espinosas altas, generalmente en filas transversales en las crestas de las ondulaciones; lámina bordeada de 2-3 filas de células estrechas marronosas; margen fuertemente dentado desde el ápice hasta los $2 / 3$ de la lámina; células hexagonales o elíptico hexagonales o elíptico hexagonales transversales de 20-30 (-38) nm, que pasan a ser cuadradas y rectangulares alargadas en la base; 2-3 veces más largas que anchas, el nervio llega hasta el ápice, fuertemente espinuloso en el dorso de la parte superior; en la cara ventral de 2-4 (-6) lamelas formadas por 2-5 filas de células casi iguales lisas y redondeadas. Filidios periqueciales más largos y estrechos. Seta roja, generalmente solitaria de $2-4 \mathrm{~cm}$. Urna cilíndrica, curvada; células del exotecio de $24-25 \mathrm{~nm}$. de ancho con las paredes verticales más engrosadas que las horizontales. Esporas de $20-26 \mathrm{~nm}$. algunas veces de tamaño muy variable, finamente papilosas; opérculo subulado, curvado casi tan largo como la urna; caliptra pálida, áspera en el ápice, cubriendo una tercera parte de la cápsula; dientes del peristoma largos, lanceolados obtusos, con la línea media de color anaranjado, membrana basal rojiza. M.T.: Sant Llorenç de la Muga (Girona). Taludes húmedos en el alcornocal, $450 \mathrm{~m} .13-1-73$, leg. et det. C. Casas (BC).

Común en taludes sombríos y suelo arcilloso.

Mesófila, esciófila, terrícola.

Circumboreal. 
var. minus (Hedw.) Paris

Gametófito más reducido, no sobrepasa los $2 \mathrm{~cm}$. de alto. Seta de $1 \mathrm{~cm}$. como máximo; urna cortamente cilíndrica.

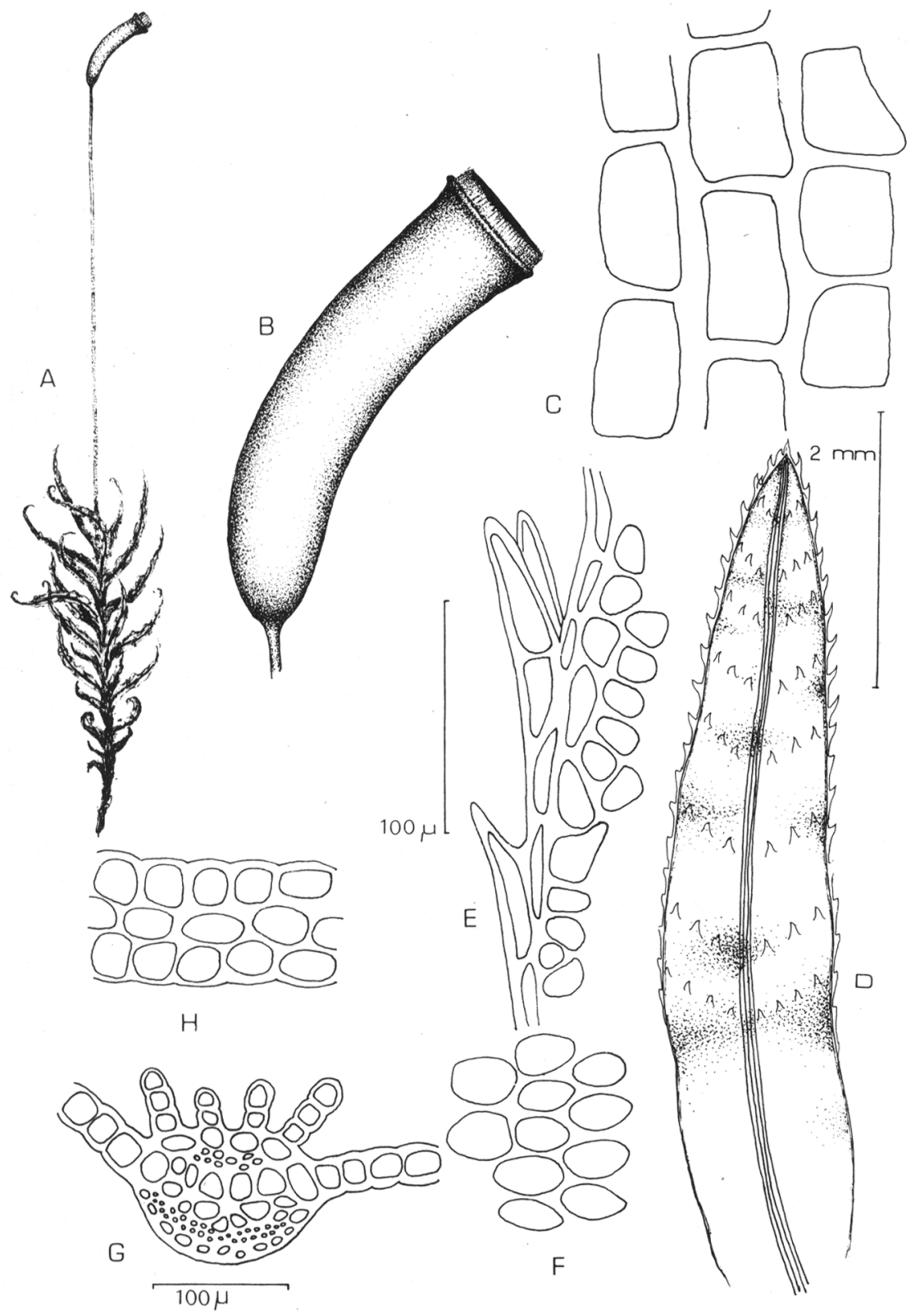

Fig. 12.-Atrichum undulatum (Hedw.) P. Beauv. A, planta (x 2). B, urna (x 9). C, células del exotecio. $D$, filidio. $E$, margen del filidio. $F$, células de la parte media de la lámina. $G$, sección del filidio. $\mathrm{H}$, lamela. 


\section{Distribución en España}

Galicia.-OR: Orense; Meirama (Run. 1964). Santa Marina (Casar. 1915). LU: Valle de Oro (Casar. 1915). C: Santiago (Casar. 1915). PO: Valle de Moreña; Valle de Cuntis (Cäsar. 1915).

Asturias.-O: Entre-ríos (Sim. et al. 1974). Cangas de Tineo; Convadonga (Casar. 1915). Villanueva de Taberga; Barrio; Presoria; Monte de la Puerca (Sim. 1973). Arbás (Lag. in Amo 1870).

País Vasco.-Común en todo el territorio (V. All. 1955).

Navarra.-NA: Vertizarana (Lac. 1885). Sierra de Leyre; Foz de Arbayún y Fuente Fría (Cas. et al. 1977b). Roncesvalles (Née in Amo 1870).

Aragón.-HU: Pineta (Cas. 1961). Bielsa (Cor. 1951; Herb. Loscos in Casar. 1915).

Catalunya.-L: Aran (Casar. 1915). Caldes de Boí (Leg. Casas BCF). B: Tibidado (Casar. 1902). Mosqueroles; Campins (Cas. 1959-60). Montserrat (E. Bout. in Amo 1870). Montnegre (Leg. Casas BCF). GE: Sant Feliu de Pallarols, ermita Ntra. Sra. de la Salud (V. All. et al. 1968). Montseny; Empalme (Casar. 1915). Arbúcies; Sant Marçal (Cas. 1959-60). Núria (Cas. 1952). Olot (Herb. F. Bolós). La Molina (Leg. Casas BCF).

León.-SA: Béjar; Candelario; El Castañar; Cantagallo; Valdesaugil; Sierra de Jálama; San Martín (Lui. 1924).

Castilla la Vieja.-S: Santander (Herb. Durieu in Sim. 1977; Casar. 1915). Espinama (P. All. 1928c). Valle del Pas (Salc. in Amo 1870). BU: Obarenes (P.All. 1930). Soncillana (Fol. et al. 1917). LO: Sierra de Cameros (Casar. 1915).

Castilla la Nueva.-M: Manzanares; Guadarrama (Lag. Cav. in Casar. 1915). Navacerrada; Cercedilla; Miraflores (Casar. et al. 1912). SG: El Paular (Née in Amo 1870).

Andalucía.-GR: Agua Agrilla de Portugos (Clem. in Amo 1870).

var. minus (Hedw.) Paris

Andalucía.-CA: Sierra de Luna (V. All. et al. 1946).

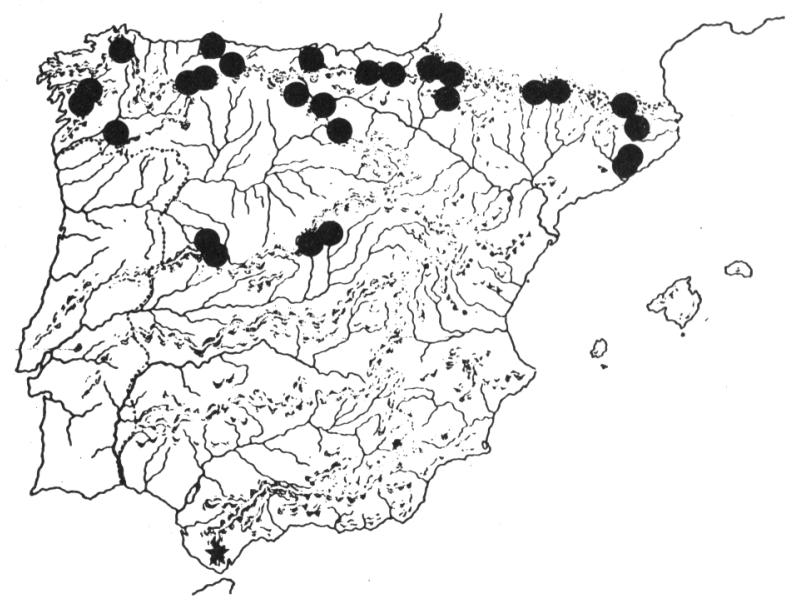

Atrichum undulatum (Hedw.) P. Beauv. Distribución conocida en España.

$\star$ var. minus (Hedw.) Paris 
Atrichum angustatum (Brid.) B.S.G., Bryol. Eur., 1844

(= Catharinea angustata Brid.)

Dioico. Gametófito de unos $3 \mathrm{~cm}$. Filidios de $4-5 \mathrm{~mm}$. crispados en estado seco, erecto-patentes de lisos más o menos ondulados en estado húmedo; estrechamente ligulado-lanceolados, ligeramente ensanchados en la base; la parte dorsal superior de la lámina dentada con numerosas o pocas células espinosas; margen de borde distinto fuertemente dentado por encima de la mitad de la lámina; nervio marrón-rojizo tuerte que llega hasta el ápice, con células espinosas en la parte dorsal superior; en la ventral de (3)-4-7 lamelas formadas por 5-9 filas de células; células más o menos hexagonales de $10-16(-20) \mathrm{nm}$, las basales a menudo papilosas, cuadradas o rectangulares, estrechas en el margen. Seta púrpura generalmente solitaria. Unna purpura estrechamente cilindrica erecta o ligeramente curvada; células del exotecio de 20 hasta $36 \mathrm{~nm}$. de ancho, rectangulares con las paredes verticales más gruesas; peristoma alto, dientes irregulares, membrana basal alta. Esporas
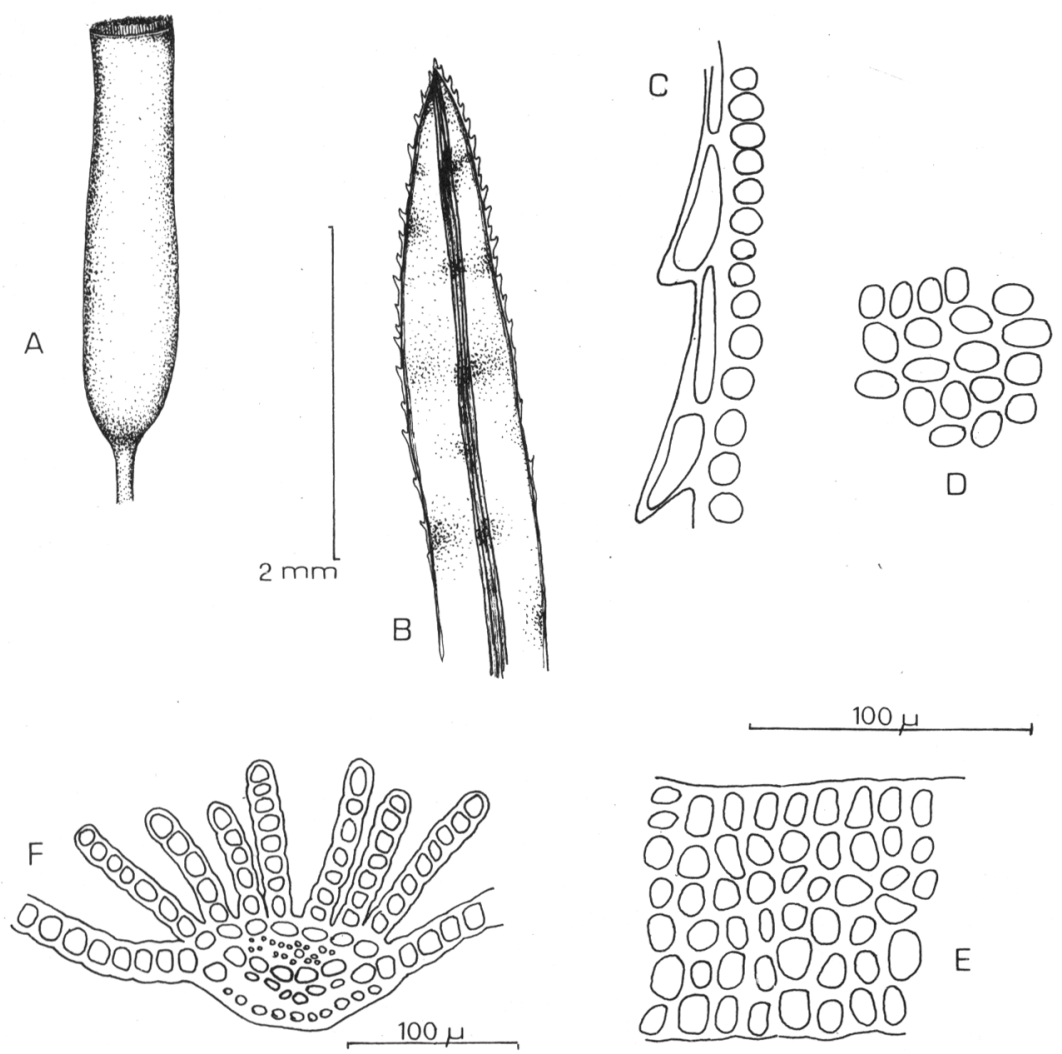

Fig. 13.-Atrichum angustatum (Brid.) B.S.G. A, urna (x 12). B, filidio. C, margen del filidio. $\mathrm{D}$, células medias del filidio. E, lamela. F, sección del filidio. 
de 10-14 nm, pálidas casi lisas. Taludes y rellanos húmedos sobre suelo silíceo. M.T.: Maçanet de Cabrenys (Girona), talud sombrío subiendo a Les Salines, 24$\mathrm{X}-74$, leg. et det. C. Casas (BC).

Mesófila, esciófila, terrícola, probablemente calcífuga.

Subatlántica.

\section{Distribución en España}

Galicia.-PO: Castro-Loureiro (Casar. 1905).

País Vasco.-SS: Monte Jaizquíbel (V. All. 1955). BI: Ellorio (V. All. 1955).

Catalunya.-GE: Montseny (Llenas in Casar. 1905). Sta. Fe del Montseny (V. All. et al. 1946). Sant Llorenç de la Muga (Bru. et al. 1974).

B: Campins; Mosqueroles (Cas. 1959-60).

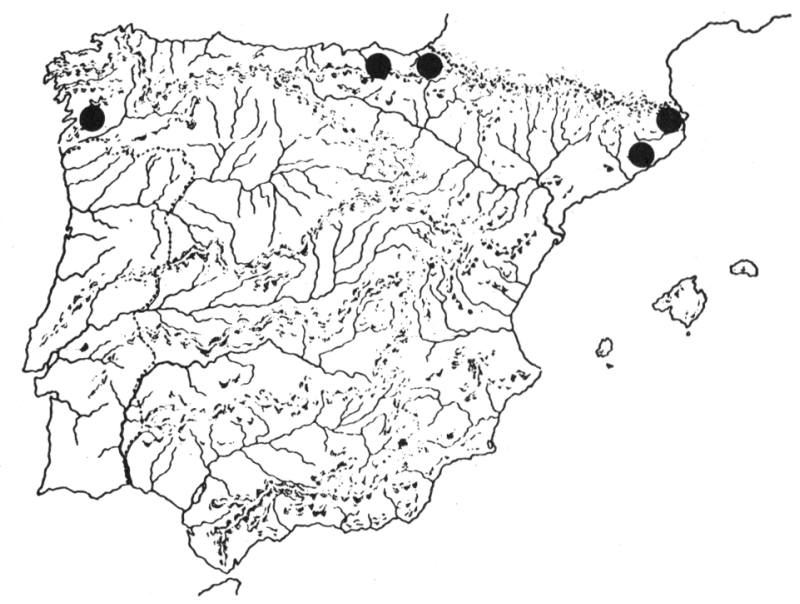

Fig. Atrichum angustatum (Brid.) B.S.G. Distribución conocida en España.

OLIGOTRICHUM Lam. et Cand., Fl. Franç. 1805.

Dioico. Caulidio simple sobre un rizoma subterráneo.

Filidios anchamente lanceolados o ligulados, cóncavos, más o menos incurvados en la parte superior, la base ancha poco envainadora; margen sin borde, entero o finamente denticulado en la parte superior; nervio ancho que acaba en el ápice o es cortamente excurrente; lamelas en ambas caras, en la ventral altas sinuosas de células casi uniformes, en la parte superior de la dorsal algunas lamelas cortas; células de la parte media redondo-cuadradas o hexagonales, rectangulares en la base. Parafisos masculinos filiformes, los femeninos más grandes y espatulados. Seta gruesa más o menos curvada. Urna oval o cilíndrica normalmente èrecta y simétrica, lisa; estomas en la base; dientes del perístoma (32) pálidos; opérculo cónico redondeado con pico corto o largo; caliptra con pelos esparsos. 
Oligotrichum hercynicum (Hedw.) Lam. et Cand. Fl. Franç. 1805

Dioico. Gametófito de 1-2,5 cm. Caulidios rígidos. Filidios de 4-5 x 1,5 mm de incurvados a crispados en estado seco, erecto-patentes, más o menos incurvados en ¿stado húmedo, ovalado-lanceolados o ligulado-lanceolados, cóncavos con el ápici inculado; margen plano sin borde, entero o finamente denticulado; nervio fuerte que a caba en el ápice; 10-16 lamelas en la cara ventral fuertemente sinuosas, ocupando un tercio o la mitad de la lámina, de 11-13 células de alto, iguales, en los dos te rcios superiores de 2-4 lamelas en la cara dorsal de 1-3 células de alto; células de la parte media de la lámina irregularmente hexagonales, pequeñas rectangulares en la base de $12-14 \mathrm{~nm}$. Filidios periqueciales más estrechos y largos. Seta lisa gruesa amarilla de 1,5-3,5 cm. Urna erecta o poco inclinada oval cilíndrica de 3-4 de
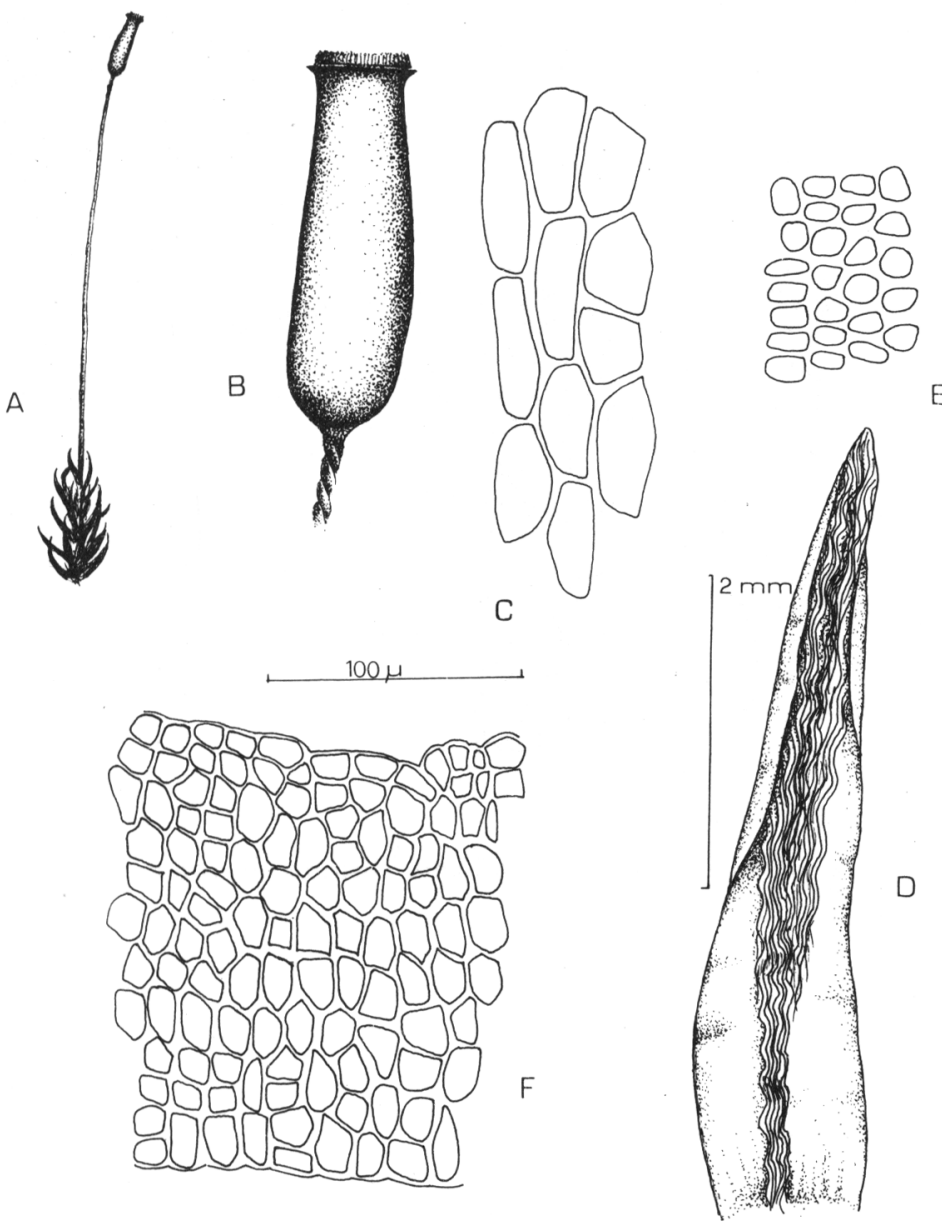

Fig. 11.-Oligotrichum hercynicum (Hedw.) Lám. \& Cand. A, planta (x 2). B, urna (x 12). C, células del exotecio. D, filidio. E, células de la parte media de la lámina. F, lamela. 
largo y 1-1,5 de diámetro; células del exotecio rectangulares; estomas anchos numerosos en la parte inferior de la urna; dientes del perístoma pálidos, cortos desiguales; opérculo cónico redondeado cortamente rostrado. Esporas de $12-15 \mathrm{~nm}$. casi lisas.

Céspedes verdes, o amarillo verdosos hasta marrón rojizo en hábitats secos o húmedos en suelo ácido raramente calcáreo, arenoso, margoso o turboso cerca de torrentes o lagos... M.T.: Costabona, Setcases (Girona) 13-8-78. Leg. Maria Caselles, det. C. Casas. Esporófito corresponde a unas muestras de Andermatt (Suiza) (BC). Saxícola o terrícola, mesófila.

Circumboreal.

\section{Distribución en España}

Andorra.-Subiendo al Coma-Pedrosa (Cor. 1897).

Aragón.-HU: Lago Urdiceto (Cas. 1961). Puerto de' Benasque (Spr. 1849).

Catalunya.-GE: Costabona (Leg. M. Caselles BCB). Vallferrera (Leg. Reinoso) BCB.

León.-LE: Brañuelas (P. All. 1928c).

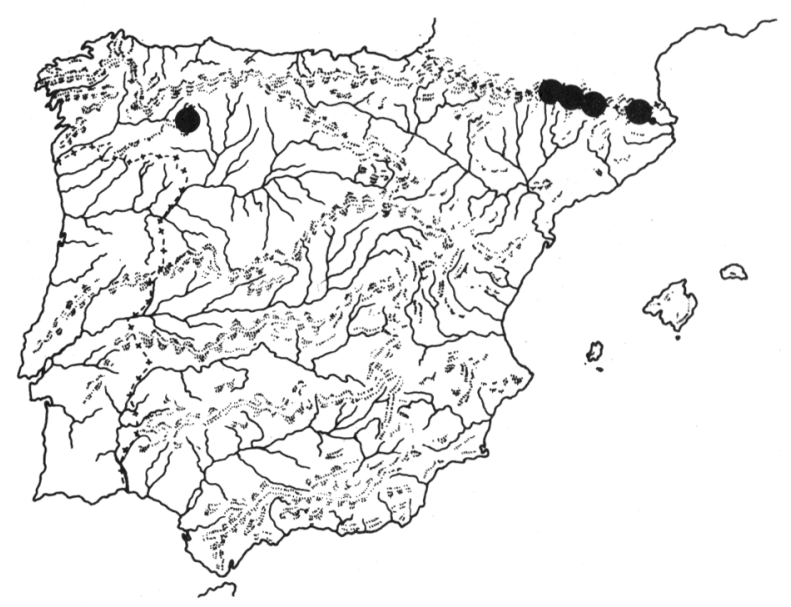

Oligotrichum bercynicum (Hedw.) Lam. et Cand. Distribución conocida en España 
BIBLIOGRAFIA

ACUÑA, A., CASAS, C., COSTA, M., FUERTES, E., LADERO, M., LOPEZ, M. L., SIMO, R. M. y VARO, J. -1974- Aportaciones al conocimiento de la flora briológica española. Notula I: El Cabo de Gata (Almería). Anal. Inst. Bot. Cavanilles 31: 59-95. Madrid.

ADE, A. \& KOPPE, Fr. -1942- Beitrag zur Kenntnis der Moostlora der atlantischen Inseln und der pyrenaischen Halbinsel. Hedwigia 81: 1-36. Dresden.

ALLORGE, P. - 1928a- Bryotheca iberica. 1re. Série n. 1-50, Espagne: 1-29. Paris.

- 1928b. Notes sur la tlore bryologique de la Péninsule lbérique. I. Muscinées récoltées par M. Roger Heim dans la Chaine Cantabrique. Rev. Bryol.nouv sér. 1: 53-58. Paris.

- 1928c. Notes sur la tlore bryologique de la Péninsule Ibérique. II. Muscinées de la provincia de León. Rèr. Bryol. noù. sér. 1: 137-150. Paris.

- 1930. Notes sur ta tlore bryologique de la Péninsule lbérique. VI. Muscinées de la province de Burgos récoltees par le frère Sennen. Rez. Bryol. nouv. sér. 3: 193-196. Paris.

- 1934. Notes sur la tlore bryologique de la Péninsule Ibérique. IX. Muscinées des provinces du Nord et du Centre de l'Espagne. Rev. Bryol. Lichénol. 7: 249-301. Paris.

- 1935. La végétation muscinale des Pinsapares d'Andalousie. Arcbiv. Mus. Hist. Nat. 12: $535-547,3$ pl. Paris.

ALLORGE, V. - 1955- Catalogue préliminaire des Muscinées du Pays basque français et espagnol. Rer. Bryol. Lichinol. 24: 96-131; 248-333. Paris.

- et ALLORGL, P. - 1945- La végétation et les groupements muscinaux des montagnes d'Algésiras. Mim. Mus. Nac. Hist. Nat. 21: 85-116. Paris.

- et Allorge, P. -1946- Notes sur la tlore bryologique de la Penínsule Ibérique. X. Muscinees du Sud et de l'Est de l'Espagne. Revo. Bryol. Lichénol. 15: 172-200. Paris.

- et CASAS, C. -1958-Contribución a la tlore bryologique de l'Espagne. Rev. Bryol. Lichinol. 27: 55-65. Paris.

- et CASAS, C. -1962a-Au sujet des Bryophytes récoltées au cours de l'excursion de l'Association Internationale de Phytosociologie dans les Pyrénées franco-espagnoles, (22-29 mai 1960). Rev. Bryol. Lichénol. 31: 213-238. Paris.

- y CASAS, C. -1962b-Contribution a la flore bryologique du Val d'Aran. Actasterier Congr. Intern. Est. Pirenaicos 3: 163-177. Zaragoza.

- y CASAS, C. -1968- Contribución al estudio de la flora briológica catalana. II. Briótitos del llano de Olot y montañas próximas. Collect. Bot. 7: 47-68. Barcelona.

- y CASAS, C. -1976- Contribución al estudio de la flora briológica catalana. III. Musgos y Hepáticas del Valle de Nuria. Collect. Bot. 10: 13-28. Barcelona.

- CASAS, C. y SERO, P. -1962c-Contribución al estudio de la flora briológica catalana. I. Briótitos de los montes de Prades. Collect. Bot. 6: 331-348. Barcelona.

- und RICHARDS, P.W. -1956-. Bryophytes collected in Spain during the Tenth 1.P.E. in 1953. Veroff. Geobotanisches Institut Rübel in Zürich 31: 250-267. Bern.

AMO, M. del -1870-Flora criptogámica de la Peninsula Ibérica. 623-791. Granada.

BARNOLA, J. - 1920 - Notas titostáticas sobre la Vegetación Briológica de las cercanías del lago de Bañolas. Broteria 18: 64-73. Braga.

BOISSIER, E. -1839-1845- Voyage botanique dans le midi de l'Espagne. 693-699. Gide et Cie. Paris.

BRAUN-BLANQUET, J. -1948- La Végetation alpine des Pyrénées orientales. Consejo Superior Investigationes Cientificas 9 Bot. 1: 1-306. Barcelona.

BRUGUES, M., CASAS, C. y CROS, R. M. -1974-Aportación a la briotlora catalana. Leucobryum juniperoideum (Brid.) C. Mull. en los alcornocales del alto Ampurdán. Anal. Inst. Bot. Cazanilles 31: 109-117. Madrid. 
CASARES GIL, A. -1902-Catálogo de las Muscíneas de los alrededores de Barcelona. Bol. Soc. Esp. Hist. Nat. 2: 327-333. Madrid.

- 1905. Nota briológica. Bol. R. Soc. Esp. Hist. Nat. 5: 175-180. Madrid.

- 1915. Enumeración y distribución geográfica de las Muscíneas de la Penísula Ibérica. Trab. Mus. Nac. Cien. Nat. Ser. Bot., 3 mapas 8: 1-179. Madrid.

- y BELTRAN BIGORRA, F. -1912- Flora briológica de la Sierra de Guadarrama. Trab. Mus. Cien. Nat. Ser. Bot. 12: 1-50. Madrid.

CASAS, C. -1951a- Algunas briófitas del macizo de Garraf. Collect. Bot. 3: 69-75. Barcelona.

- 1951b. Hepaticae, Musci in LOSA, M. y MONTSERRAT, P. Aportación al conocimiento de la flora de Andorra. Consejo Superior Investigaciones Cientificas 53. Bot. 6: 174-181. Zaragoza.

- 1953 (1952). Contribución al estudio de la Flora Briológica del Norte de España. Anal. Jard. Bot. 10 (2): 257-273. Madrid.

- 1952. Una excursión briológica al Valle de Nuria. Collect. Bot. 3: 199-206. Barcelona.

- 1954. Aportaciones a la brioflora catalana. Excursiones briológicas por el Alt Berguedá. Collect. Bot. 4: 141-159. Barcelona.

- 1958. La flora briológica del Cap de Creus. Pharmacia Mediterranea 2: 440-459. Pavia.

- 1959-1960 (1958-1959). Aportaciones a la flora briológica de Cataluña. Musgos y hepáticas del Montseny. Anal. Inst. Bot. Cavanilles 16: 121-226;17: 21-174. Madrid.

- 1961 (1960). Contribución al estudio de la flora briológica de los Pirineos Centrales. Musgos y hepáticas de Bielsa (Huesca). Anal. Inst. Bot. Cavanilles 18: 269-288. Madrid.

- 1972. Brioteca Hispanica 1969. Acta Phytotax. Barc. 10: 18-26. Barcelona.

- 1975a. Aportación al estudio de la flora briológica española. Musgos y hepáticas de las provincias de Soria, Logroño, Burgos y Segovia. Anal. Inst. Bot. Cavanilles 32: 731-762. Madrid.

- 1975b. Brioteca Hispanica 1970. Acta Phytotax. Barc. 15: 27-33. Barcelona.

- 1975c. Brioteca Hispanica 1971. Acta Phytotax. Barc. 15: 34-38. Barcelona.

- FUERTES, E., SIMO, R.M. y VARO, J. -1977a- Aportaciones al conocimiento de la flora briológica española. Notula II: Sierra de Albarracín. Acta Pbytotax. Barc. 21: $19-41$.

- SERO, P., UBACH, M. y VIVES, J. -1956- Flora briológica de las comarcas barcelonesas. Collect. Bot. 5: 119-141. Barcelona.

- FUERTES, E. y LADERO, M. -1977b-Zur Moosflora von Navarra (Nord-Ost-Spanien). 7. Mitteilung: Sierra de Leyre. Herzogia 4: 345-350.

CILlerO, M. -1945- Aportación a la flora briológica española. Anal. Jard. Bot. Madrid 5: 365-376. Madrid.

CODINA, J. -1908- Apuntes para la flora de La Sellera y su comarca. Colegio de Médicos de la Prov. de Gerona: 70. Girona.

COLMEIRO, M. -1849- Apuntes para la flora de las dos Castillas. 164-169. Madrid.

- 1889. Enumeración y revisión de las plantas de la península hispano-lusitánica e islas Baleares con la distribución de las especies y sus nombres vulgares, tanto nacionales como provinciales. (Monocot. y Criptógamas). 5: 473-571. Madrid.

CORBIERE, L. -1897- Muscinées rares ou nouvelles pour les Pyrénées. Rev. Bryol. 24: 54 55. Paris.

CORTES, C. -1949- (1947). Aportaciones a la Briológica española. Anal. Jard. Bot. Madrid 8: 339-355. Madrid.

- 1951 (1948-1949). Aportaciones a la Briología española. Anal. Jard. Bot. Madrid 9: 259-333. Madrid.

- 1953 (1952). Aportaciones a la Briología española. Datos para la brioflórula extremeña. Anal. Inst. Bot. Cavanilles 11 (1): 161-249. Madrid.

- 1954 (1953). Aportaciones a la Briología española. Estudio crítico de los musgos citados en los "Anales de Ciencias Naturales" de 1802. Anal. Inst. Bot. Cavanilles 12 (1): 299-394. Madrid. 
ESTEVE, F., VARO, J. y ZAFRA, M. L. -1975- Catálogo de Briófitos de la provincia de Granada. Trab. Dep. Bot. Univ. Granada 3: 3-44. Granada.

FOLCH, R. y ESTEBANEZ, R. -1917-Algunas Muscíneas encontradas en la comarca de Soncillana. Bol. R. Soc. Esp. Hist. Nat. 17: 352-353. Madrid.

FRUCTUOSO, G. -1914- Excursiones briológicas por la provincia de Badajoz. Trab. Mus. Nac. Cien. Nat. Ser. Bot. 6: 1-16. Madrid.

FUERTES, E. y LOPEZ FERNANDEZ, M. L. -1975- Flora briofítica navarra. I. Sierra del Perdón y Sierra de Alaiz. Anal. Inst. Bot. Cavanilles 32: 125-144. Madrid.

FUERTES, E. Flora briofítica navarra. II. Encinar de Domeño. Actas VII Congr. Intern. Est. Pirenaicos (en prensa).

- GARCIA GOMEZ, R. y BASCONES, J. C. -1975- Flora briofítica navarra. IV. Estudio de la vertiente suroccidental de la Sierra de Sarvil. Anal. Inst. Bot. Cavanilles 32: 923-952. Madrid.

GAY, A. -1836- Duriaei iter Asturicam Botanicam. Anno 1835 susceptum. Ann. Soc. Not. Paris 20 ser. 6: 113-137; 213-225; 340.

GEHEEB, A. -1874- Beitrag zur Moosflora von Spanien. Flora 33: 1-6.

GIL, J. A. y VARO, J. -1973- Contribución al estudio briológico de Sierra Nevada. II. El Barranco de San Juan. Trab. Dep. Bot. Univ. Granada 2: 63-79. Granada.

GONZALEZ, R. -1883- Apuntes para la flora de la provincia de Sevilla. Anal. Soc. Esp. Hist. Nat. 12: 14-23. Madrid.

HÖHNEL, Fr. -1895- Beitrag zur Kenntniss der Laubmoosflora des Hochgebirgstheiles der Sierra Nevada in Spanien. Sitzungsberichten der Kaiserl. Akad. Wissens. Match. Natur. 104-336. Wien.

HUSNOT, P. T. -1876- Guide du Bryologue dans les Pyrénées. Rev. Bryol.3: 7-11; 69-70. Paris.

HUSNOT, P.T. -1884-1890- Muscología gallica. Paris.

LACOIZQUETA, J. M. - 1885- Catálogo de las plantas del Valle de Vertizarana. Anal. Hist. Nat. 191-204. Madrid.

LERESCHE, L. et LEVIER, R. - 1880-Deux excursions botaniques dans le Nord de l'Espagne et le Portugal en 1878-1879. 164-179. Lausanne.

LOSCOS, F. y PARDO, J. -1867- Serie imperfecta de las plantas a ragonesas espontáneas particularmente de las que habitan en la parte meridional. 469-481. Alcañiz.

LUISIER, A. -1918- Fragments de Bryologie Ibérique. 14. Mousses de Galice. Broteria Ser. Bot. 16: 123-142. Braga.

- 1924. Musci Salmanticenses. Mem. R. Acad. Cien. Exa. Fis. Nat. 3: 1-280. Madrid.

MASFERRER, R. -1877-Recuerdos botánicos de Vich. Anal. Soc. Esp. Hist. Nat. 6: 69-70. Madrid.

MÜLLER, K. -1854- Bryologische Beiträge zu einer Flore der Pyrenäen, des nördlichen und des südlichen Spaniens. Bot. Zeitung 19: 313-320.

RENAUlD, F. -1878-1885- Notice sur quelques mousses des Pyrénées. Rev. Bryol. 11: 5254; 12: 31-32. Paris.

RICHARDS, P.W. -1932- Note on the Bryophytes of the "Waterfall Valley" near Algecieras: an outpost of the Atlantic flora. Rev. Bryol. Lichénol. 5: 6-9. Paris.

RIVAS MATEOS, M. - 1897- Estudios preliminares para la flora de la provincia de Cáceres. Anal. Soc. Hist. Nat. Ser. 2a. 6: 209-212. Madrid.

RÖLL, J. -1897- Beiträge zur Laubmoostlora von Spanien. Hedwigia 36: 37-42. Dresden.

RUNGBY, S. -1964- A contribution to the Bryophytic Flora of Spain, Especially the Environs of Hellin. Botaniska Notiser 117: 167-172 Lund.

SERO, P. - 1946- Contribución al conocimiento de la flora briológica de Aralar (Guipúzcoa). Collect. Bot. 1: 41-47. Barcelona.

- 1956. Musgos de los alrededores de Bohí (Pirineo de Lérida). Homenaje póstumo al Dr. D. Francisco Pardillo Vaquer. Universidad de Barcelona 179-188. Barcelona.

SIMO, R. M. - 1973- Estudio de la flora briológica del Puerto Ventana (Asturias). Bol. Inst. Estud. Asturianos 17: 1-220, 3 fot. $1 \mathrm{~m}$. Oviedo. 
- 1977. Catálogo de Briótitos recolectados por Durieu de Maisonneuve en la Península Iberica. Acta Phytotax. Barc. 21: 53-69. Barcelona.

- y AlONSO, N. 1974. Panorama briológico del Cabo de Peñas (Asturias). Bol. Inst. Estud. Asturianos 19: 1-30. Oviedo.

- y VIGON, E. -1973- Hymenophyllum tunbrigense (L.) Sm. y Trichomanes speciosum Willd. novedades para la tlora asturiana. Bol. Inst. Estud. Asturianos 16: 207-215. Oviedo.

- y VIGON, E. -1975-Adelanthus decipiens (Hook.) Mitt. novedad para la flora espanola. Aita Phytotax. Barc. 15: 23-26. Barcelona.

SLOOVER, I. L. de -1967- Quelques Bryophytes recueillis a Majorque. Les Naturalistes belges 18: 389-394. Bruxelles.

SPRUCE, R. -1849- The Musci and Hepaticae on the Pyrenees. Ann. Magz. Natur. Hist. 103-216, $3 \mathrm{pl}$.

STORMER, P. - 1969- Mosses with a Western and Southern distribution in Norway. Universitesforlaget 1-288. Oslo.

THERIOT, J. -1932- Mousses de la Sierra Nevada récoltées par le Dr. M. Maire en 1925. Cavanillesia 5: 36-40, 1 Tab. Barcelona.

TONGLET, A. -1903- Musgos del Moncayo. Bol. Soc. Aragonesa Cien. Nal. 2: 73-74. Zaragoza.

- 1906. Lista de Musgos y Hepáticas de Ortigosa de Cameros (Logroño). Bol. Soc. Aragonesa Cien. Nal. 5: 111-114. Zaragoza.

VAYREDA, E. -1982- Cataleg de la Flora de la Vall de Núria. Associació d'Excursions Catalana 88-91. Barcelona.

VIVES, J. -1947- Notas sobre la flora briológica de la comarca de La Selva. Collect. Bot. 1 : 123-125. Barcelona.

WARNSTORF, C. -1911- Verzeichnis der von M. Fleischer 1908 wahrend der Monate April und Mai in Sudtrankreich und Spanien beobachteten Laub-, Leber-, und Torfmoose. Hedwigia 50: 189-203. Dresden.

ZAFRA. M.L. y VARO, J. -1974-Contribución al estudio Briológico de Sierra Nevada. I. Los Peñones de San Francisco. Anal. Inst. Bot. Cavanilles 31: 97-108. Madrid.

ZETTERSTEDT, J.E. -1865- Pyreneernas Mossvegetation. Kongl. Svenska Vetenskaps-Akad. Handlingar 5 (10): 1-51.

ZUBIA, I. -1921- Flora de la Rioja 2: 90-195. Logroño. 